\title{
Personnel Neutron Dosimetry at Department of Energy Facilities
}

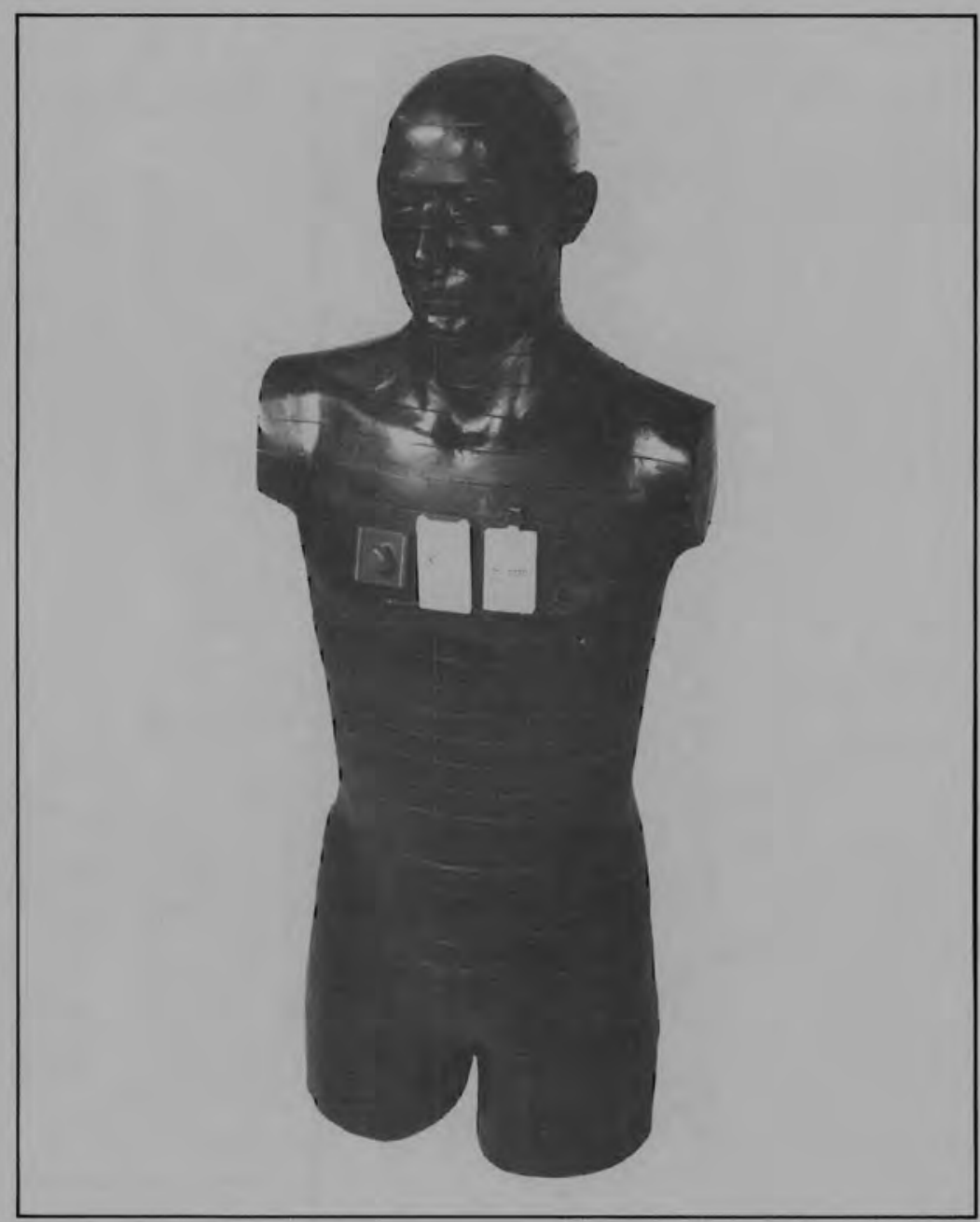

Prepared for the U.S. Department of Energy under Contract DE-AC06-76RLO 1830

Pacific Northwest Laboratory Operated for the U.S. Department of Energy by Battelle Memorial Institute 


\title{
NOTICE
}

This report was prepared as an account of work sponsored by the United States Government. Neither the United States nor the Department of Energy, nor any of their employees, nor any of their contractors, subcontractors, or their employees, makes any warranty, express or implied, or assumes any legal liability or responsibility for the accuracy, completeness or usefulness of any information, apparatus, product or process disclosed, or represents that its use would not infringe privately owned rights.

The views, opinions and conclusions contained in this report are those of the contractor and do not necessarily represent those of the United States Government or the United States Department of Energy.

\author{
PACIFIC NORTHWEST LABORATORY \\ operated by \\ BATTELLE \\ for the \\ UNITED STATES DEPARTMENT OF ENERGY \\ Under Contract DE-AC06-76RLO 1830
}

\author{
Printed in the United States of America \\ Available from \\ National Technical Information Service \\ United States Department of Commerce \\ 5285 Port Royal Road \\ Springfield, Virginia 22151
}

Price: Printed Copy $\$$

$\because$ Microfiche $\$ 3.00$

NTIS

- Pages Selling Price

$\begin{array}{ll}001-025 & \$ 4.00 \\ 026-050 & \$ 4.50 \\ 051-075 & \$ 5.25 \\ 076-100 & \$ 6.00 \\ 101-125 & \$ 6.50 \\ 126-150 & \$ 7.25 \\ 151-175 & \$ 8.00 \\ 176-200 & \$ 9.00 \\ 201-225 & \$ 9.25 \\ 226-250 & \$ 9.50 \\ 251-275 & \$ 10.75 \\ 276-300 & \$ 11.00\end{array}$




\section{3}

PERSONNEL NEUTRON DOSIMETRY

AT DEPARTMENT OF ENERGY FACILITIES

L. W. Brackenbush, Principal Investigator

G. W. R. Endres, Contributor

J. M. Selby, PNL Project Manager

E. J. Vallario, DOE Project Manager

August 1980

Prepared for

the U.S. Department of Energy

under Contract DE-AC06-76RLO 1830

Pac if ic Northwest Laboratory

Richland, Washington 99352 


\title{
FOREWORD
}

The National Council on Radiation Protection and Measurements has recently issued a statement regarding dose limits for neutrons. The changes proposed in the statement present substantive problems with regard to personnel exposures to neutrons and point to the need to reassess the adequacy of current neutron dosimetry practices. Generally, the same types of dosimeters, i.e., NTA films and TLD-albedo, have been used over the past 15 years. More recently, other dosimetry methods such as track etch with polycarbonates and CR-39 have been developed. However, these should be recognized as interim systems pending the development of better, more applicable dosimeters.

In addition to advances in personnel neutron dosimeters, improvement in the characterization of neutron fields and spectra at work locations is needed. In many situations, a large fraction of the dose may be delivered by neutrons with energies less than $100 \mathrm{keV}$. While some of the recent developments in track etch techniques show promise for accurate detection of energies above $200 \mathrm{keV}$, improvement in detector accuracies and sensitivities to energies below $200 \mathrm{keV}$ is also needed. With DOE encouragement and funding, the National Bureau of Standards has established a monoenergetic beam capability for neutrons with energies between thermal and $1.2 \mathrm{MeV}$. This facility provides the ability to determine the energy response of various dosimeters.

In the context of these problems and possible solutions, investigators in the United States are encouraged to increase their collaboration with international authorities. The DOE Neutron Dosimetry Workshop provides a forum for the exchange of ideas and new techniques and should continue to be used for this purpose. We believe there is an urgent need to initiate new programs oriented to the resolution of neutron dosimetry problems, and this report is intended to provide a basic reference point for the development of new ideas.

\author{
E. J. Vallario \\ Assistant Chief/Manager \\ Health Physics Programs \\ Division of Operation and \\ Environmental Safety \\ U.S. Department of Energy
}




\section{ACKNOWLEDGMENTS}

The authors would like to acknowledge the efforts of J. L. Baer, the technical editor who was faced with the problem of making a coherent document from a number of diverse sources of information. We also appreciate the efforts of the health physicists at the various DOE sites who took the time to fill out the dosimeter survey questionnaire. Finally, we wish to acknowledge the efforts of the Ad Hoc Committee and attendees of the neutron dosimetry workshop in Seattle who corrected mistakes in the draft and who made many helpful suggestions, especially those concerning establishing a neutron dosimetry "think tank" and lead laboratory for research on personnel neutron dosimeters. The recommendations of this document reflect many of their ideas. 


\section{SUMMARY OF FINDINGS AND RECOMMENDATIONS}

Accurate neutron dosimetry is difficult because of the wide range of neutron energies that must be measured and the wide range of linear energy transfers (LETS) associated with neutron irradiations. The dose equivalents delivered by a single neutron vary by a factor of 70 in the range of neutron energies found in Department of Energy (DOE) facilities. A comparison of indicated and actual dose equivalents during a recent survey of personnel dosimetry in the United States showed that about $45 \%$ of the dosimeter results were in error by more than 60\%. The need for improved accuracy for personnel neutron dosimeters has also been demonstrated by several dosimeter intercomparison studies.

The purpose of this study was to assess the state of personnel neutron dosimetry at DOE facilities. To accomplish this, a survey of the personnel dosimetry systems in use at major DOE facilities was conducted, a literature search was made to determine recent advances in neutron dosimetry, and several dosimetry experts were interviewed. We concluded that personnel neutron dosimeters do not meet current needs and that serious problems exist now and will increase in the future if neutron quality factors are increased and/or dose limits are lowered.

\section{FINDINGS}

A significant number of persons are exposed to neutrons in DOE facilities. The dosimetry survey data indicated that over 30,000 persons at DOE facilities have a potential for neutron exposure and are issued dosimeters. While this report addresses only needs within DOE, workers regulated by the Nuclear Regulatory Commission (NRC) and the Department of Defense (DOD) also have a potential for neutron exposure. It has been estimated that about 52,000 persons who work under NRC regulations are exposed to neutrons. (a) In addition, thousands

(a) Data from U.S. Nuclear Regulatory Commission's draft Eleventh Annual Occupational Exposure Report. Data include 46,000 workers at reactors and 6,000 we 11 loggers. 
of workers are exposed to neutrons from accelerators utilized by the medical community. In a 1l, over 100,000 persons in the United States may be exposed to neutrons.

The introduction of nuclear fusion technology may further increase this number if fusion proves to be feasible and large numbers of fusion plants are built for electric power production. A problem already exists because increasing numbers of persons must enter neutron fields inside the containment vessels of commercial nuclear power plants while the reactors are operating. $A$ solution to DOE problems could contribute to the solution of the neutron dosimetry problems of other federal agencies.

Concern about the effects of low-level radiation is increasing, and the degree of hazard may be higher than has been assumed in the past. Proposals have been made that the National Council on Radiation Protection and Measurements (NCRP) significantly increase the quality factors for neutrons. These proposals are being studied by NCRP, which recently issued a "Statement on Dose Limit for Neutrons" indicating that the maximum permissible neutron dose limits may be reduced by anywhere from a factor of 3 to a factor of 10 .

Current neutron dosimetry is inadequate for many neutron irradiation situations. Department of Energy sites are still using nuclear track emulsion (NTA film) or thermoluminescence (TLD-albedo) neutron dosimeters, both of which suffer from energy dependence problems. Personnel dosimeters in routine use today will not be adequate if neutron dose limits are lowered. Dosimeter accuracy needs to be improved, and the minimum detectable dose equivalent (approximately $30 \mathrm{mrem}$ or $3 \mathrm{mrad}$ for fast neutrons) needs to be lowered.

\section{RECOMMENDATIONS}

Funding of neutron dosimetry research should be increased significantly. Current DOE-sponsored research programs on personnel neutron dosimetry are estimated to be limited to about 1.5 man-years of effort. Priorities should be given to: 
- establishing a lead laboratory to direct the necessary research

- optimizing current dosimetry programs and systems

- performing research leading to the development of new types of dosimeters and neutron detection mechanisms

- establishing a neutron dosimetry "think tank" to suggest new areas of research and development and provide guidance to DOE at least until the lead laboratory is established

- establishing adequate calibration techniques and facilities

- sponsoring symposia, workshops, and intercomparison studies. 


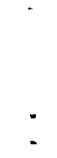

. 


\section{CONTENTS}

FOREWORD

ACKNOWLEDGMENTS $\quad$ • $\quad$ •

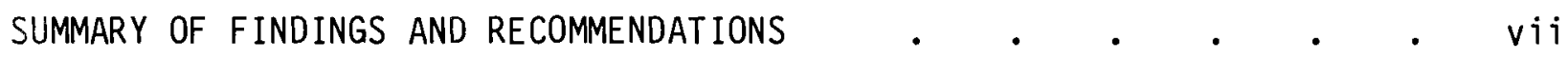

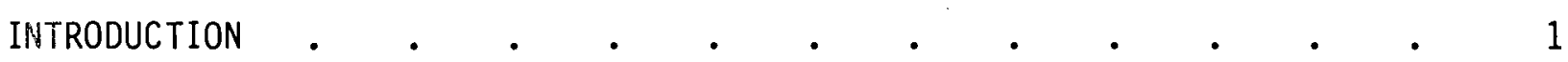

\begin{tabular}{l} 
LEGAL REQUIREMENTS AND RECOMMENDATIONS ON PERSONNEL \\
NEUTRON DOSIMETERS \\
\hline
\end{tabular}

PROPOSED CHANGES IN QUALITY FACTORS OR DOSE LIMITS FOR NEUTRONS • 3

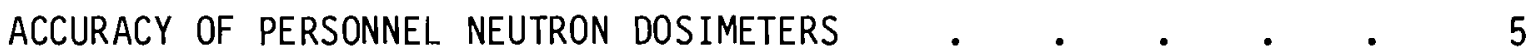

SOURCES OF INFORMATION ABOUT NEUTRON DOSIMETRY $\quad$ • $\quad$ • $\quad$ • $\quad$ • 6

PERSONNEL DOSIMETRY INTERCOMPARISON STUDIES • • • • • • 7

SUMMARY OF TYPES OF NEUTRON DOSIMETERS

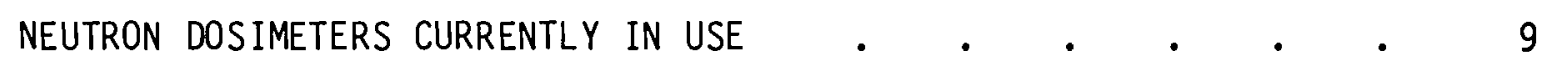

POSSIBLE FUTURE NEUTRON DOSIMETERS •

DOSIMETRY AT DEPARTMENT OF ENERGY SITES •

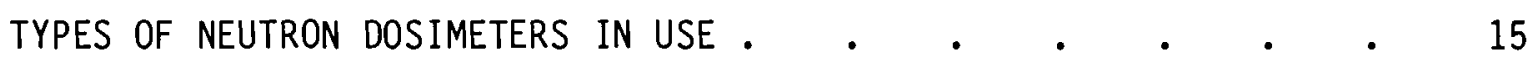

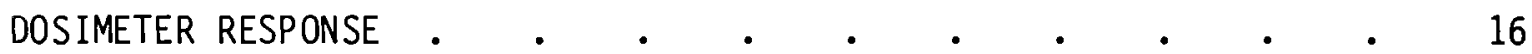

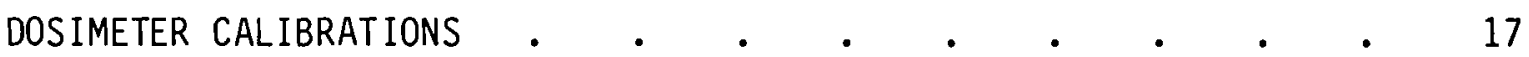

TYPES OF FACILITIES IN WHICH PERSONNEL NEUTRON

DOSIMETERS ARE USED •

NUMBERS OF PERSONS USING PERSONNEL DOSIMETERS $\quad$. . . . $\quad 20$

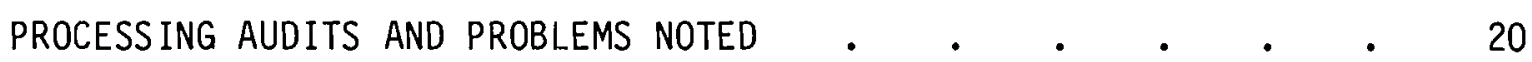

NEUTRON DOSIMETRY: CURRENT PROBLEMS AND AREAS FOR IMPROVEMENT

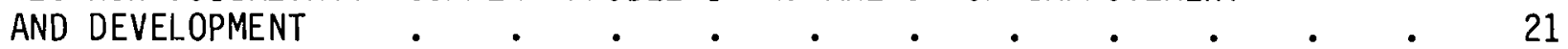

SUMMARY OF CURRENT PROBLEMS IN NEUTRON DOSIMETRY . . . • $\quad 21$

IMPROVEMENTS IN EXISTING DOSIMETRY • • • • • • • • $\quad$ • 22 


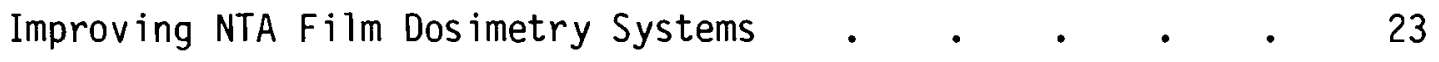

Improving Thermoluminescence-Albedo Dosimetry Systems . $\quad 23$

Accuracy Verification Through System Audits . . . . 28

RECOMMENDATIONS FOR FUTURE PERSONNEL NEUTRON DOSIMETERS $\quad$ • $\quad 28$

Combination TLD-Albedo and Track Etch . . . . . 28

Combination TLD-Albedo and NTA Film $\quad$. $\quad . \quad . \quad . \quad . \quad 28$

Combination TLD-Albedo and Deep-Trap TLD $\quad$. $\quad$. $\quad$. 29

Other New Types of Dosimeters . $\quad . \quad \ldots \quad . \quad . \quad . \quad . \quad 29$

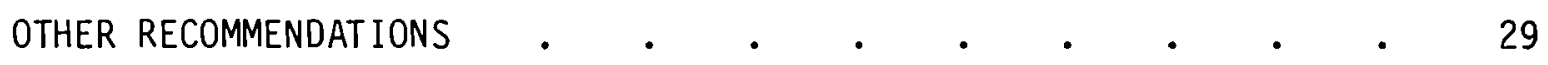

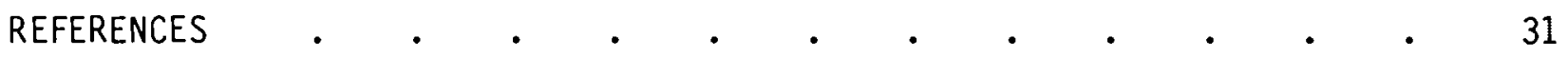

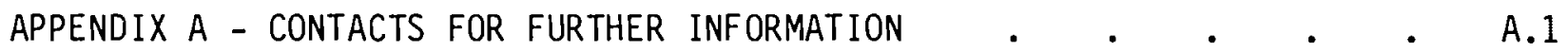

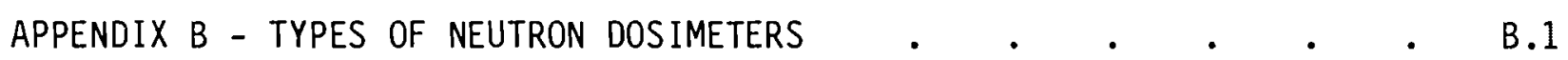

APPENDIX C - PERSONNEL NEUTRON DOSIMETER SURVEY FORM AND RESPONSES • $\quad$ C.1 


\section{FIGURES}

1 Effective Neutron Energy as a Function of the Ratio of $23-\mathrm{cm}$ to $6.7-\mathrm{cm}$ Polyethylene Sphere Responses

\section{$\underline{\text { TABLES }}$}

1 Comparison of Ideal Dosimeter with Dosimeters Used at

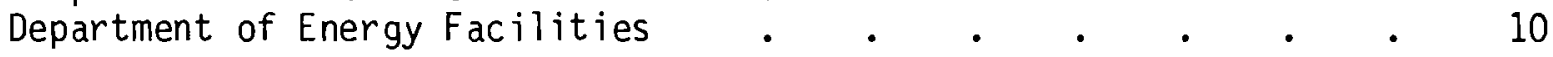

2 Comparison of Ideal Dosimeter with Track Etch Dosimeters . • 11

3 Comparison of Ideal Dosimeter with Combination Dosimeters

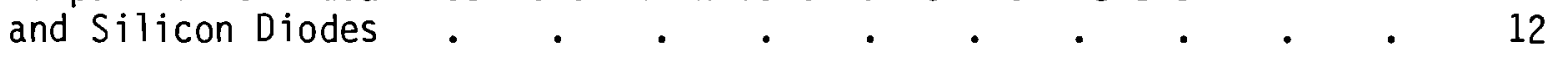

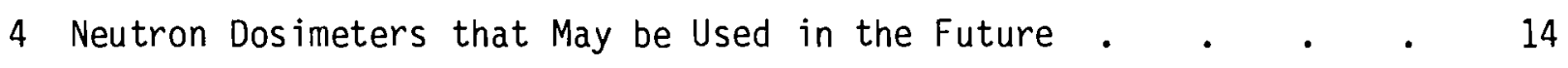


PERSONNEL NEUTRON DOSIMETRY

AT DEPARTMENT OF ENERGY FACILITIES

\section{INTRODUCTION}

Accurate neutron dosimetry is difficult to obtain because of the wide range of neutron energies that must be measured and because of the variations in linear energy transfer (LET) from neutron-induced secondaries. The dose equivalents delivered by single neutrons vary by a factor of 70 in the range of neutron energies found in Department of Energy (DOE) facilities. The detection systems currently used for personnel neutron dosimetry at DOE sites -primarily nuclear track emulsion (NTA film) dosimeters and thermoluminescencealbedo dosimeters -- have been in use for more than 15 years. Although these systems are still being improved, they have energy response problems that make them inadequate for general, widespread use.

Concern about the effects of low-level radiation may lead to a lowering of the maximum permissible dose for neutrons (National Council on Radiation Protection and Measurements [NCRP] 1980). The degree of hazard from high-LET radiations such as neutrons is under question and may be greater than has been assumed in the past (Rossi 1977a). If the neutron dose limits are decreased or the neutron quality factors are increased or redefined, the personnel neutron dosimeters routinely used today will be inadequate.

This study was undertaken for DOE by the Pacific Northwest Laboratory (a) to assess the state of personnel neutron dosimetry at DOE facilities, to delineate possible problem areas, and to offer suggestions for improving personnel neutron dosimetry. This purpose was accomplished by the following:

(a) Operated by Battelle Memorial Institute. 
- a survey of the personnel neutron dosimetry systems in use at DOE facilities

- a literature survey of techniques that may be useful for neutron dosimetry

- discussions with dosimetry experts at several DOE sites concerning improved dosimetry techniques and neutron dosimeters that may be used in the future.

Background information about neutron dosimetry is provided in the remainder of this introduction. A brief description of the types of personnel neutron dosimeters in use today, and of some devices that may be suitable for future use, follows. The results of the survey conducted at major DOE sites are then presented, followed by a summary of the current state of personnel neutron dosimetry and a discussion of possible ways of improving dosimetry systems.

\section{LEGAL REQUIREMENTS AND RECOMMENDATIONS ON PERSONNEL NEUTRON DOSIMETERS}

The requirements for radiation protection at DOE facilities are contained in DOE Manual Chapter 0524, "Standards for Radiation Protection" (U.S. Department of Energy 1978). This document contains little guidance specific to personnel neutron dosimeters. However, it does require compliance with standards of performance for personnel neutron dosimeters developed by the American National Standards Institute (ANSI). The U.S. Nuclear Regulatory Commission (NRC) has also developed performance standards, but they do not specifically apply to DOE contractors. The standards with which NRC contractors must comply are: Section 20.202, "Personnel Monitoring," of Title 10, Chapter 20, Code of Federal Regulations (10 CFR 20.202), Regulatory Guide 8.14 (U.S. Nuclear Regulatory Commission 1980), and ANSI N319-1976 (ANSI 1976). Some of these requirements are summarized here:

1. Personnel neutron dosimeters shall be capable of measuring neutron dose equivalents in the range of $300 \mathrm{mrem}$ to 10 rem per quarter of a year. 
2. The accuracy of 10 dosimeters exposed to an unmoderated ${ }^{252} \mathrm{Cf}$ source in the range of 100 mrem to 3 rem shall be within $+50 \%$ of the true dose equivalent.

3. The neutron dosimeter shall be able to measure 1 rem of neutrons in the presence of 3 rem of gamma rays with an energy of $\geq 500 \mathrm{keV}$ in mixed radiation fields.

4. The neutron dosimeter shall meet the above requirements when subjected to the following environmental conditions:

a. temperature extremes of $0^{\circ} \mathrm{C}$ and $45^{\circ} \mathrm{C}$ for 1 week

b. relative humidity of $90 \%$ for 1 week

c. mechanical shock from a drop from a height of $1.5 \mathrm{~m}(4.9 \mathrm{ft})$

d. exposure to light (sunlight or normal room light).

In addition, ANSI has published a draft of a proposed standard, ANSI N13.11, which lists criteria to be used for testing personnel dosimeters (ANSI 1978).

The National Council on Radiation Protection and Measurements (NCRP) has published several reports that give recommendations for personnel dosimetry. These recommendations are generally adhered to at DOE facilities. Protection Against Neutron Radiation, NCRP Report No. 38 (1971), contains information important for personnel dosimetry, such as definitions, dose-equivalent limits, quality factors, conversion factors for changing flux to dose-equivalent rate, and depth-dose relationships for neutrons of various energies. Instrumentation and Monitoring Methods for Radiation Protection, NCRP Report No. 57 (1978), contains information on suggested types of neutron dosimeters, methods for estimating whole-body or organ doses and dose equivalents, and suggested dosimeter exchange periods, accuracy requirements, records, etc.

\section{PROPOSED CHANGES IN QUALITY FACTORS OR DOSE LIMITS FOR NEUTRONS}

The concept of quality factor was introduced in health physics to account for the degree of hazard from equal doses of different types of radiation. For a given dose (in rads or Greys), for example, neutrons produce more biological damage than gamma rays. Quality factor is a function of the LET produced by each type of radiation. 
Radiation dose limits are based on a limited knowledge of a number of effects that occur at a fairly high dose. It has been assumed (the so-called "linear hypothesis") that, for any one type of radiation, the radiation risk is directly proportional to the radiation dose. Rossi points out that the linear hypothesis has been applied to both high-LET radiation (neutrons) and low-LET radiation ( $x$ and gamma rays) (Nuclear News 1980). This implies that quality factors and relative biological effectiveness (RBE) have a fixed value regardless of the dose level involved in a neutron or gamma-ray exposure. However, Rossi states, theoretical and experimental evidence indicate that the RBE increases with decreasing dose or decreasing level of effect, "reaching values that can be 100 or more for the doses of interest in radiation protection... [and therefore] current estimates of cancer risk are too high for lowLET radiations, but too low for high-LET radiations" (Nuclear News 1980). Rossi has also proposed that the entire basis for the definition of quality factor be changed (Rossi 1977a and 1977b; Rossi and Mays 1978). The effect of these proposals may we 11 be a significant increase in the quality factors for fast neutrons.

The NCRP is currently considering changing the neutron dose limits. Their recently issued "NCRP Statement on Dose Limit for Neutrons" (NCRP 1980) indicates that they may recommend lowering neutron dose limits by anywhere from a factor of 3 to a factor of 10 below the current limits. (The current annual dose-equivalent limit is $5 \mathrm{rem}$. This corresponds to $2.5 \mathrm{rad} / \mathrm{yr}$ for a quality factor of 2 for thermal neutrons, or $0.45 \mathrm{rad} / \mathrm{yr}$ for a quality factor of 11 for $0.5-\mathrm{MeV}$ neutrons.) One method of effecting these reduced dose 1 imits would be to increase neutron quality factors by factors of 3 to 10 . However, NCRP noted in the statement that the basis for defining quality factors may change substantially, and its future recommendations may be more than an updating of previous NCRP recommendations or a simple increase of the neutron quality factors. No formal action has been taken to date, and the decision may be contingent upon the recommendations of a future report by the Committee on the Biological Effects of Ionizing Radiation of the National Research Council. 
Adopting the proposed changes -- either a significant increase in the quality factors for neutrons or a reduction in the limit for exposure to neutron radiation -- would cause serious problems for neutron dosimetry.

ACCURACY OF PERSONNEL NEUTRON DOSIMETERS

It is difficult to assess the accuracy of neutron dosimeters because of the diversity of dosimeter designs in use. Each DOE site has developed its own neutron dosimeter to meet problems specific to the site. Even tests comparing dosimeters may not be indicative of dosimeter accuracy because of differences between the neutron spectra in the test situation and those in the field exposure. Some general conclusions can be drawn, however. The accuracy of neutron dosimeters is generally poorer than that of gamma dosimeters, as evidenced by Plato and Hudson's dosimeter intercomparison studies (1979), dosimeter intercomparisons at Oak Ridge National Laboratory (Gilley, Dickson and Christian 1976; Gilley and Dickson 1979), European intercomparisons (Schraube and Paretzke 1976), and international comparisons (Caswe11, Goodman and Colvett 1975; Goodman 1976). A recent dosimeter survey indicates that under well defined irradiation conditions, the difference between the actual and indicated dose equivalent exceeds $60 \%$ in about $45 \%$ of the neutron dosimeters surveyed (Chabot, Jimenez and Skrable 1978).

There are several reasons for the relatively poor accuracy of neutron dosimeters. First, all neutron dosimeters in use today are energy sensitive, and the neutron energies encountered in DOE facilities vary from $0.025 \mathrm{eV}$ (therma 1) to $300 \mathrm{GeV}$. Second, neutron quality factors vary between 2 and 11, whereas gamma rays have only a single quality factor of 1 . Third, many neutron dosimeters are sensitive to gamma rays, and because the two types of radiation usually occur together, the interpretation of neutron dosimeter readings is complicated.

In many instances, it is difficult for personnel neutron dosimeters to meet the recommendations of NCRP Report No. 57, Instrumentation and Monitoring Methods for Radiation Protection (NCRP 1978), concerning the accuracy of 
personnel dosimeters. The report states that the precision of a dosimeter measurement should be $\pm 10 \%$ and that the accuracy of the measurement will depend on the level of exposure:

- at levels less than $1 / 4$ of the maximum permissible dose (MPD), a factor of 2 is acceptable;

- at the level of MPD, $\pm 30 \%$ accuracy should be achieved;

- at levels higher than the MPD, such as those that might occur during emergencies, an accuracy of better than $+20 \%$ is desirable.

SOURCES OF INFORMATION ABOUT NEUTRON DOSIMETRY

Several recent articles provide information on personnel neutron dosimetry. An extensive survey of personnel dosimetry practices in the United States, recently completed by Chabot, Jimenez and Skrable (1978), contains some information on neutron dosimetry. Griffith et al. have published an excellent review of recent developments in personnel neutron dosimeters and dosimetry techniques (1979). Another review is contained in Oak Ridge report ORNL/TM-6756 (Barton and Easterly 1979).

A forum for the exchange of information among national and international experts is provided by the DOE-sponsored Neutron Dosimetry Workshops. (a) Seven workshops have been held to date, and the proceedings of all but the third have been reported by the Pacific Northwest Laboratory as listed below:

$\begin{array}{cccc}\text { Workshop } & \text { Date } & & \text { Report No. } \\ 1 & & & \text { BNWL-1340 } \\ 2 & 1969 & & \text { BNWL-1616 } \\ 4 & 1971 & \\ 5 & 1973 & \text { BNWL-1717 } \\ 6 & 1975 & \text { BNWL-1934 } \\ 7 & 1977 & \text { PNL }-2449 \\ & 1978 & \text { PNL }-2807\end{array}$

(a) For further information, see the list of contacts in Appendix A. 
PERSONNEL DOSIMETRY INTERCOMPARISON STUDIES

Personnel dosimeter intercomparison studies are performed annually at Oak Ridge Nationa 1 Laboratory's Dosimetry Applications Research Facility (DOSAR). (a) For these studies, the Health Physics Research Reactor (HPRR) is used. The HPRR is a sma11, unmoderated, fast-pulse reactor, which is operated in a low-power steady-state mode for the dosimeter intercomparisons. The reactor is used unshielded, or with one or more of the following shields: 12-cm-thick (5-in.) Lucite shields, 20-cm-thick (8-in.) concrete shields, or a combination shield of 5-cm-thick (2-in.) stee 1, 13-cm-thick (5-in.) steel, and 15-cm-thick (6-in.) concrete. The different shield materials provide different neutron spectra, which have been characterized by the two-dimensional transport code DOT (Rhoades and Mynatt 1973). The radiation fields are also characterized by other devices such as thermoluminescence dosimeters (TLDs), small Geiger-Muller (GM) counters, and tissue-equivalent ion chambers (Sims 1980). The results of the fourth and fifth intercomparison studies are given in reports by Dickson (1980) and Sims (1980).

(a) For further information, see the list of contacts in Appendix A. 


\section{SUMMARY OF TYPES OF NEUTRON DOSIMETERS}

Many types of neutron detectors may be useful as personnel neutron dosimeters. Because of the volume of the data on these detectors, the details of how they function have been placed in Appendix B. Some of the more pertinent information is summarized in brief descriptions and tables in this section.

To give a basis of comparison among the different dosimeter types, we have selected the following criteria as representative of the "ideal" personnel neutron dosimeter:

- sensitivity, or lower detection limit - The dosimeter should be able to measure down to at least 10 mrem for almost any neutron energy.

- interference from other radiations - The dosimeter should be insensitive to photons and beta particles.

- stability - The dosimeter should not exhibit fading with time.

- environmental factors - The dosimeter should not be affected by ambient temperature, humidity, or pressure, or be sensitive to mechanical shock.

- energy response - The dosimeter's response should follow the dose equivalent as a function of neutron energy. If this is not possible, the dosimeter should indicate neutron fluence and energy or neutron absorbed dose (in rads) and quality factors.

- cost - The dosimeter materials should have a reasonable cost to allow widespread use. The readout of the dosimeter should be capable of being automated to reduce readout costs.

- other factors - The personnel dosimeter should be easily worn by the user. It should not present unacceptable toxicity hazards. 
NEUTRON DOSIMETERS CURRENTLY IN USE

Only two types of personnel neutron dosimeters are widely used at DOE facilities: 1) nuclear track emulsion (NTA film) dosimeters and 2) thermoluminescence (TLD-albedo) dosimeters. A comparison between the hypothetical ideal dosimeter and the NTA film and TLD-albedo dosimeters is given in Table 1.

While not currently used as personnel dosimeters at DOE facilities, track etch devices have been under investigation for more than 15 years and are being used for routine neutron dosimetry in Europe. The two basic types of track etch dosimeters are 1) fission track etch dosimeters, in which the neutrons interact with fissionable foils to produce fission fragments that damage the plastic or mica film and tracks that are visible when the film is etched, and 2) recoil track etch dosimeters, in which neutrons interact with carbon or hydrogen in plastics to produce tracks. A comparison between the ideal dosimeter and the track etch dosimeters is given in Table 2.

\section{POSSIBLE FUTURE NEUTRON DOSIMETERS}

Several other types of neutron detectors have been studied and might, with additional research, be usable as personnel neutron dosimeters. Combination dosimeters combine TLD-albedo dosimeters with track etch or deep-trap TLDs to compensate for the energy dependence of the TLD-albedo dosimeters. Silicon diodes have been shown through preliminary research to have a flat energy response and could be used as an integrating dosimeter if the lower detection limit can be improved. These two detectors are compared with the ideal dosimeter in Table 3.

Finally, many different types of neutron detectors may be used as neutron dosimeters in the future, but considerble research on the lower detection limit, energy response, etc. will be required before these neutron detectors can become useful personnel dosimeters. These devices include the following: 


\section{TABLE 1. Comparison of Ideal Dosimeter with Dosimeters Used at DOE Facilities}

\section{Factor}

Lower detection limit

Interference from other

radiations

Stability

Environmental factors

Energy response/

angular respons

ம
Ideal Dosimeter

Measures down to $10 \mathrm{mrem}$

No interference from photons or other particles in mixed fields

No fading problems with time

Unaffected by temperature, humidity, mechanical shock

Response to neutrons of different energies similar to response of soft $t$ issue OR dosimeter must indicate neutron energy to allow proper interpretation; responds to all incident neutron angles

Moderate cost; dosimeter readout capable of being

All neutron energies
NTA Film Dosimeter

Poor sensitivity except for high energies; lower detection 1 imit 250 mrem under favor-

able conditions

Serious interference problem: photons darken film, making it difficult to read tracks

Serious fading problem -- can be compensated for by

$H$ igh humidity and temperatures cause track fading; special packaging needed

Responds to neutron energies above $0.7 \mathrm{MeV}$; response

(tracks/rem) varies by

factor of 3 from $0.7 \mathrm{Me}$

to $14 \mathrm{MeV}$; some angular

dependence

Film inexpensive, but optical readout tedious

High-energy neutrons

Relatively inexpensive useful for high-energy neutrons

Track fading from environmental factors; relatively poor sensitivity (need to count many tracks for statistical accuracy); poor response to intermediate
and slow neutrons
TLD-Albedo Dosimeter

Lower detection limit of 1 to

50 mrem for fast neutrons

TLD sensitive to neutrons and photons; photon response must be subtracted out

Can be made stable with proper annealing

Relatively unaffected by temperature, humidity, shock; can be influenced by dirt, oil, environmental contaminants

Very poor energy response; varies by factor of 600 from $1 \mathrm{eV}$ to $10 \mathrm{MeV}$; some angular dependence

Moderate initial expense; TLD $c$ an be reused many times after annealing; readout easily

Almost any location where calibration factor has been established, except for high-

Useful for moderated neutron spectra; used where spectrum does not change much; inexp sive; can be automated to persons

Severe energy response problem: dose equivalent is overest imated for low-energy neutrons unless special

calibrations are performed 


\section{TABLE 2. Comparison of Ideal Dosimeter with Track Etch Dosimeters}

$$
\text { Factor }
$$

Lower detection limit

Interference from other radiations

Stability

Environmental factor

Energy response/

angular response

$\longmapsto$
Ideal Dosimeter

Measures down to $10 \mathrm{mrem}$

No interference from

photons or other particles

No fading problems with time

Unaffected by temperature, humidity, mechanical shock

Response to neutrons of different energies similar to response of soft tissue neutron energy to allow proper interpretation; responds to all incident neutran angles

Cost

Moderate cost; dosimeter readout capable of being automated

Application

All neutron energies

Advantages

Dis advantages

(i) Registered trademark of Pittsburgh Plate Glass.

Fp-237
Fission Track Etch Dosimeters

Estimated 10 to $100 \mathrm{mrem}$ depending on energy and foil size

Free of $\gamma$ interference below photo-fission threshold

Good track stability

Unaffected by moderate temperature $(: 100 \mathrm{C})$ or by mechanical shock

Response matches doseactor of 2 for most energies

High initial cost for Np-237 foils; inexpensive plastic readout using spark counters

Most neutron energies except thermal

Good energy response; inexpensive readout if spark counting used

Gamma dose to wearer; administrative problems with special nuclear material; high cost for $\geq 100$ mrem depending on foil size

Free of $r$ interference below photo-fission threshold

Good track stability

Unaffected by temperature, humidity, mechanical shock

Responds to neutrons with energies above $1 \mathrm{MeV}$

Moderate expense; automated rearout using spark counters

High-energy neutrons Moderate expense; Th- 232
exempted from NRC licensing if used for dosimeters

Poor sensitivity; detection; use of radio active material
Recoil Track Etch Dosimeters

20 to 60 mrem depending on type of plastic, no. of artifacts in plastic, and neutron energy

Free of $\gamma$ interference

Good track stability

Unaffected by normal ambient temperature, humidity, mechanical shock

Polycarbonate - threshold of $1.5 \mathrm{MeV} ; \mathrm{Cr}-39^{\circledR}$ - threshold of $\sim 200 \mathrm{keV}$

Inexpensive; semiautomated lectrochemical etch

Fast neutrons

Moderate expense; good for fast neutrons

Energy response does not match that of tissue 


\section{TABLE 3. Comparison of Ideal Dosimeter with Combination Dosimeters and}

\section{Silicon Diodes}

\begin{tabular}{|c|c|}
\hline Factor & Ideal Dosimeter \\
\hline Lower detection 1 imit & Measures down to $10 \mathrm{mrem}$ \\
\hline $\begin{array}{l}\text { Interference from other } \\
\text { radiations }\end{array}$ & $\begin{array}{l}\text { No interference from photor } \\
\text { or other particles in mixed } \\
\text { fields }\end{array}$ \\
\hline Stability & No fading problems with tin \\
\hline Environmental factors & $\begin{array}{l}\text { Unaffected by temperature, } \\
\text { humidity, mechanical shock }\end{array}$ \\
\hline $\begin{array}{l}\text { Energy response/ } \\
\text { angular response }\end{array}$ & $\begin{array}{l}\text { Response to neutrons of } \\
\text { different energies similar } \\
\text { to response of soft tissue } \\
\text { OR dosimeter must indicate } \\
\text { neutron energy to allow } \\
\text { proper interpretation; } \\
\text { responds to all incident } \\
\text { neutron angles }\end{array}$ \\
\hline $\cos t$ & $\begin{array}{l}\text { Moderate cost; dosimeter } \\
\text { readout capable of being } \\
\text { automated }\end{array}$ \\
\hline
\end{tabular}

Application

Advantages

Disadvantages

\section{Combination Dosimeters}

TLD-Albedo \& Track Etch
1 to 20 mrem depending on energy

$\gamma$ response must be sub tracted out for TLDS

Good stability -- little fading

Unaffected by ambient temperatures, humidity, mechanica? shock

Wide energy range: TLOS -slow \& intermediate energies track etch -. high energies

Moderate -- includes costs for two systems: TLD \& track etch

Overcomes severe energy dependence of TLD-albedo

Expense of two dosimetry systems: TLD \& track etch more work needed on energy response of CR-39ब

\section{Widespread use}

\section{TLD-Albedo \& Deep-Trap TLD}

About $1 \mathrm{mrem}$, depending on energy

$\gamma$ response must be subtracted out for TLS

Stability of deep-trap TLD not known

Probably not affected by temperature, humidity, mechanical shock

Energy response of deep-trap TLO not known

nexpensive -- low-cost addition of deep-trap TLO to TLD-albedo dosimeter system

widespread use possible

Overcomes severe energy dependence of $T L D$-albedo least expensive way to existing TLD-albedo systems

Little known about deeptrap TLD systems
Silicon Diodes

$500 \mathrm{mrem}$ for $f$ ast neutrons Insensitive to $r$ and $B$

Conflicting data on stability - can apparently be used as ting dosimeter

Unaffected by environmental factors

Relatively flat energy response from $200 \mathrm{keV}$ to $16 \mathrm{MeV}$
Moderate to high -- could be reduced if diodes made in quantity

Fast neutrons

Integrating capability; flat energy response from $200 \mathrm{keV}$ to $16 \mathrm{MeV}$

Not sensitive enough; poor consistency of response between diodes -- each may require its own calibration. more research needed 
- plastics - Certain plastics exhibit changes in electrical conductivity when irradiated.

- electrets - These electric analogs of permanent magnets undergo changes in electric field strength when exposed to radiation.

- the superheated drop detector - Small drops of superheated liquid in a viscous gel vaporize when struck by neutrons.

- electronic devices - With the introduction of inexpensive microelectronics, different types of neutron detectors, such as recoil chambers, 3 He counters, and low-voltage capacitors with fissionable foils, can be made into neutron-sensitive alarming dosimeters.

- thermally stimulated exoelectron emission (TSEE) devices - When certain materials are heated, they emit electrons in proportion to the absorbed dose.

- lyoluminescent chemicals - Some organic compounds emit light when they are dissolved; the amount of light is proportional to the dose received by the compound.

The characteristics of these neutron detectors are listed in Table 4. For a more extensive description of each of the devices mentioned here, with references, consult Appendix B. 
TABLE 4. Neutron Dosimeters that May be Used in the Future

\begin{tabular}{|c|c|c|c|c|c|c|}
\hline Factor & Plastics & Electrets & $\begin{array}{l}\text { Superheated } \\
\text { Drop Detectors }\end{array}$ & Electronic Devices & $\begin{array}{c}\text { Thermally } \\
\text { Stimulated Exoelectron } \\
\text { Emission Devices } \\
\end{array}$ & $\begin{array}{l}\text { Lyoluminescent } \\
\text { Chemicals }\end{array}$ \\
\hline $\begin{array}{l}\text { Lower detection } \\
\text { limit }\end{array}$ & $\begin{array}{l}10 \text { mrem for fast } \\
\text { neutrons }\end{array}$ & Unk nown & $\begin{array}{l}\text { Can be made to any } \\
\text { sensitivity }\end{array}$ & Depends upon device & High sensitivity & $\begin{array}{l}\text { Lower detection } \\
\text { limit } 400 \mathrm{mrem}\end{array}$ \\
\hline $\begin{array}{l}\text { Interf erence } \\
\text { from other radia- } \\
\text { tions }\end{array}$ & $\begin{array}{l}\text { Unaffected by } Y \\
\text { and } B\end{array}$ & Sensitive to $Y$ & Not sensitive to $Y$ & $\begin{array}{l}\text { Apparently can } \\
\text { separate } y \text { and } \\
\text { neutron events }\end{array}$ & $\begin{array}{l}\text { Neutron response } \\
\text { small fraction of } \\
\gamma \text { response }\end{array}$ & Sensitive to $\gamma$ \\
\hline Stability & Unknown & Unknown & Unknown & Unknown & Unknown & $\begin{array}{l}\text { Unknown over long } \\
\text { times }\end{array}$ \\
\hline $\begin{array}{l}\text { Environmental } \\
\text { factors }\end{array}$ & Unk nown & Unknown & $\begin{array}{l}\text { Sensitive to temper- } \\
\text { ature and pressure } \\
\text { changes }\end{array}$ & $\begin{array}{l}\text { Unknown, but should } \\
\text { have little effect }\end{array}$ & $\begin{array}{l}\text { Should have little } \\
\text { effect }\end{array}$ & $\begin{array}{l}\text { Should have little } \\
\text { effect }\end{array}$ \\
\hline $\begin{array}{l}\text { Energy response/ } \\
\text { angular response }\end{array}$ & Unknown & Unknown & Unknown & $\begin{array}{l}\text { Energy response } \\
\text { matches that of } \\
\text { tissue within a } \\
\text { factor of } 2 \mathrm{from} \\
0.5 \mathrm{eV} \text { to } 14 \mathrm{MeV}\end{array}$ & Unknown & $\begin{array}{l}\text { Unknown, but should } \\
\text { match energy } \\
\text { response of tissue }\end{array}$ \\
\hline $\cos t$ & Inexpensive & Moderate & Inexpensive & Very expensive & $\begin{array}{l}\text { Inexpensive to } \\
\text { moderate }\end{array}$ & $\begin{array}{l}\text { Expensive -- } \\
\text { ultrapure chemicals } \\
\text { required }\end{array}$ \\
\hline Application & Fast neutrons & Fast neutrons & Fast neutrons & Alarming dosimeter & Fast neutrons & Fast neutrons \\
\hline Advantages & $\begin{array}{l}\text { Appears to work } \\
\text { from } 10 \text { mrem to } \\
70 \text { rem }\end{array}$ & $\begin{array}{l}\text { Already used as } \\
\text { alarming r dosi- } \\
\text { meter; can be used } \\
\text { to determine any } \\
\text { dose below alarm } \\
\text { level; response } \\
\text { should be similar } \\
\text { to response of } \\
\text { tissue }\end{array}$ & $\begin{array}{l}\text { Inexpensive; self- } \\
\text { reading capability; } \\
\text { can be made into } \\
\text { neutron spectro- } \\
\text { meter }\end{array}$ & Real-time dosimetry & Moderate costs & $\begin{array}{l}\text { Possible tissue- } \\
\text { like response }\end{array}$ \\
\hline Disadvantages & $\begin{array}{l}\text { Litt le known about } \\
\text { use as dosimeter; } \\
\text { must be read out at } \\
\text { constant tempera- } \\
\text { ture }\end{array}$ & $\begin{array}{l}\text { Response to neutrons } \\
\text { unknown }\end{array}$ & $\begin{array}{l}\text { Nothing known about } \\
\text { energy response and } \\
\text { stability; energy } \\
\text { threshold changes } \\
\text { with temperature }\end{array}$ & $\begin{array}{l}\text { Very high costs; } \\
\text { conceptual devices } \\
\text { only - few have } \\
\text { been built yet }\end{array}$ & $\begin{array}{l}\text { Neutron response } \\
\text { much smaller than } \\
\text { response; not suited } \\
\text { for use in mixed } \\
\text { radiation fields }\end{array}$ & $\begin{array}{l}\text { Need to improve } \\
\text { lower limit of } \\
\text { detection by } 2 \\
\text { orders of } \\
\text { magnitude }\end{array}$ \\
\hline
\end{tabular}




\section{DOSIMETRY AT DEPARTMENT OF ENERGY SITES}

Information on the present state of neutron dosimetry at DOE facilities was obtained by contacting dosimetry experts at various DOE laboratories and by the use of a personnel neutron dosimeter survey. The survey was sent to health physicists at 17 major DOE facilities. Health physicists at nine of the sites returned the survey forms; information for the other eight sites was obtained by telephone interviews.

Appendix $C$ presents the survey form with a brief tabulation of the responses from the 17 participating facilities. Because one of the participants did not wish to be identified, the information obtained in the survey is not identified by site names.

\section{TYPES OF NEUTRON DOSIMETERS IN USE}

Thermolumincescence-albedo dosimeters, used at 13 DOE sites, are the most widely used dosimeters. Nuclear track emulsion dosimeters are used at six sites, usually small sites where a limited number of dosimeters are issued or else sites where accelerators generate high-energy neutrons. One site uses a neutron dosimeter that employs a film packet placed next to a cadmium foil to detect slow and albedo neutrons by the capture of gamma rays from the cadmium filter. Several laboratories issue both NTA and TLD-albedo dosimeters, but only one uses a combination TLD-albedo and NTA dosimeter. In the combination dosimeter, the TLD-albedo dosimeter is used to detect low-energy neutrons and the NTA film is used to detect fast neutrons. This combination overcomes the energy response problem of the TLD-albedo dosimeter. The most recent TLDalbedo dosimeters use modifications of the Hankins calibration method (1975; see also Appendix B) to correct for the energy response.

Only one DOE laboratory is using track etch techniques for personne 1 dosimetry on an experimental basis, although several facilities reported using fission and recoil track etch dosimeters for area monitoring. Two sites are monitoring neutron dose equivalents to the hands and forearms. One site uses a special TLD-albedo wrist dosimeter; the other uses neutron-to-gamma ratios. 
However, one must use caution in applying the neutron-to-gamma ratio technique to plutonium gloveboxes. The dust layer on gloves can give a significant photon exposure even when the amount of plutonium in the glovebox is not high enough to generate neutrons.

The dosimeter readout systems used have varying degrees of automation. The NTA dosimeter systems are manual: the films are developed and read out under microscopes. Most of the TLD systems are semiautomated, i.e., the TLDs must be manually removed from the dosimeter and placed in the reader. Only two sites reported fully automated TLD readout systems. Seven sites reported that their dosimeter results are in computer files and easily accessible.

\section{DOSIMETER RESPONSE}

The effects of environmental factors on dosimeter response are reasonably well known. Nuclear track emulsion film suffers from track fading and is sensitive to temperature and humidity; it also "fogs" from low-energy gamma interference. Four sites that use NTA film reported problems with high temperatures and high humidities. At high-energy accelerator facilities, muons are interpreted as gamma exposure on the NTA film. At GeV energies, neutrons are indistinguishable from protons and other hadrons.

Thermoluminescence dosimeters also suffer from environmental effects. Two sites reported that chalk dust, dirt, and oil have been found to cause false readings unless the TLDs are thoroughly cleaned. Perfumes and some cosmetics spilled on the TLDs can cause high readings even after the TLDs have been thoroughly cleaned in alcohol. Some solvents used to clean dosimeters may fluoresce. Only one site reported problems caused by TLDs responding to ultraviolet light; this problem may be due to phosphorescence in the teflon tape used to hold the TLDs in place. One site reported that radioactive contamination on dosimeters is sometimes a problem also, but the effects can be estimated by placing new chips in the badge.

Mixed radiation fields influence the accuracy of neutron dosimeters. One site reported that NTA films fog badly when exposed to 1000 mrem of photon radiation; the effect is especially bad for low-energy photon fields such as 
those from ${ }^{241} \mathrm{Am}$ and plutonium. Mixed fields affect TLDs also, because the ${ }^{6}$ LiF chips are gamma sensitive, and the cadmium filters used to shield the ${ }^{6}$ LiF chips emit gamma rays from absorbing neutrons. Four sites reported that TLD albedo dosimeters have gamma interference problems at gamma-to-neutron ratios ranging from $4: 1$ to $20: 1$. Low-energy $\times$ rays tend to mask neutron exposures because of the methods used to correct for the photon exposure registered by the $6_{\text {LiF }}$ chip.

The lower limit of detection reported varies quite a bit depending upon the dosimeter used. Thermoluminescence dosimeters are very sensitive to lowenergy neutrons. Nuclear track emulsion dosimeters also respond to thermal neutrons via $N(n, p)$ reactions in the emulsion; however, sites using NTA dosimeters did not report the lower limit of detection for neutrons. For thermal neutrons, the lower limit of detection reported varies from $0.01 \mathrm{mrem} \pm 50 \%$ to $50 \mathrm{mrem} \pm 50 \%$, with an average of $10 \mathrm{mrem}$. For fast neutrons with energies above $100 \mathrm{keV}, 10$ sites reported lower detection limits ranging from $1 \mathrm{mrem}$ at an unknown confidence level to $50 \mathrm{mrem} \pm 50 \%$, with an average value of $30 \mathrm{mrem}$. Only three sites gave the lower detection limit for intermediate-energy neutrons (energies of $1 \mathrm{eV}$ to $100 \mathrm{keV}$ ); the values range from $10 \mathrm{mrem} \pm 40 \%$ to 35 mrem $\pm 40 \%$.

\section{DOSIMETER CALIBRATIONS}

Most DOE sites have neutron calibration sources available, even if they are not routinely used for dosimeter calibration. Some sites using the Hankins method (1975) for calibration of TLD-albedo dosimeters do not expose dosimeters to calibrated sources. Nine sites reported having PuBe sources (ranging from 1 to 160 grams); five sites have ${ }^{252} \mathrm{Cf}$ sources; four sites have $\mathrm{PuF}_{4}$ sources; one site uses a combination of $\mathrm{PuF}_{4}$ and $\mathrm{PuO}_{2}$ for a calibration source that more closely matches that in work locations. Other types of neutron sources are available (PuB and PuLi) but are not routinely used for dosimeter calibrations. Corrections for changes in source strength are applied at 5- and 10-year intervals for PuBe and every time the source is used for ${ }^{252} \mathrm{Cf}$. 
At six sites, dosimeters are usually calibrated under medium-scatter conditions (in a large room with concrete walls and floors, with the source elevated more than $1.5 \mathrm{~m}[5 \mathrm{ft}]$ above the floor). At three sites, dosimeters are calibrated in high-scatter rooms (small rooms, 3 by $6 \mathrm{~m}$ [10 by $20 \mathrm{ft}$ ], with thick concrete walls and floors and with the source within 0.9 or $1.2 \mathrm{~m}$ [3 or $4 \mathrm{ft}$ ] of the floor).

Nuclear track emulsion dosimeters are calibrated without a phantom at four sites. Thermoluminescence-albedo dosimeters must, of course, be exposed on a phantom to operate properly. Four sites reported using phantoms that are composed of water, polyethylene, lucite, or paraffin. One site uses an anthropomorphic phantom for calibrations. A recent report (Hankins 1979) notes that the size and shape of the phantom may be more important than its composition. At one site, the phantom is rotated to simulate an isotropic irradiation, and at another wrist dosimeters are placed on a water-filled phantom that is also rotated.

Eight sites have performed source calibrations, and four have sources calibrated by the National Bureau of Standards (NBS). Only two sites have made measurements to determine whether the source emits neutrons isotropically. Three sites have measured the field around the source, using a long counter to measure flux, and tissue-equivalent proportional counters and rem meters to measure dose equivalent. The remaining sites have assumed isotropic emission. Isotropic emission is a good assumption for most sources. Anisotropy measurements have been made at PNL with a PuBe source, and the anisotropy was found to be about $8 \%$ in the worst case.

Dosimeters are reported to be exposed at distances of 15 to $150 \mathrm{~cm}$ ( 5.9 to $59 \mathrm{in.}$ ) from the source. At distances of less than 40 to $50 \mathrm{~cm}(16$ to 20 in.), unusual effects are sometimes seen in the gamma-ray component, which is subtracted from the ${ }^{6} \mathrm{LiF}$ chip response. At distances beyond about $40 \%$ of the distance to the nearest wall, ${ }^{(a)}$ the room scatter predominates in the calibration of the TLD-albedo dosimeter.

(a) Eisenhauer and Schwartz, to be published. 
A single calibration factor is used at eight sites; seven sites use a variable calibration factor that accounts for changes in neutron energy and scattering conditions. The energy calibration is found by taking the ratio of the measured flux inside a $23-\mathrm{cm}-\mathrm{dia}(9-\mathrm{in}$.$) polyethylene sphere and a$ 2.6-cm-dia (3-in.) cadmium-covered polyethylene sphere (Hankins 1975; see also Appendix $B)$. One site calibrates dosimeters on phantoms in work areas where the dose-equivalent rate has been measured by other methods.

TYPES OF FACILITIES IN WHICH PERSONNEL NEUTRON DOSIMETERS ARE USED

Neutron dosimeters are used in an amazingly wide variety of DOE facilities, some of which are listed below.

Type of Facility

Nuclear reactor

Accelerator

Deuterium-tritium generator

Fusion reactor

Isotopic neutron source

Nuclear fuels fabrication

Chemical separations

Plutonium manufacture

Biological facilities

Transuranics recovery

others (waste handling, well-logging)
No. of Sites

11

11

8

3

12

7

6

8

3

5

5

Nuclear reactors, particle accelerators, and isotopic neutron sources are found at most DOE sites. Potential neutron exposure problems are also found at sites involving radioactive waste handling and well-logging using neutron sources, and at transuranic element manufacture and encapsulation facilities. 
NUMBERS OF PERSONS USING PERSONNEL DOSIMETERS

The number of persons issued neutron dosimeters at DOE facilities is quite large -- some 30,000 persons. This overall number was obtained through telephone interviews and the dosimeter survey form. Only seven of the survey respondents (from two accelerator sites, four national laboratories and one reactor site) gave the specific categories of persons issued dosimeters (see Appendix C).

According to the survey, some 3900 persons were issued NTA film dosimeters and 14,200 persons were issued TLD-albedo dosimeters. It was not possible to estimate what type of dosimeter was used by other dosimeter recipients, since many sites issue more than one type of neutron dosimeter. One respondent estimated, however, that approximately 8000 people are issued $\mathrm{Cd}-\mathrm{film}$ dosimeters, which can detect thermal and albedo neutrons by the captured gamma rays produced when cadmium absorbs a neutron. These devices are used to determine the presence of neutrons.

PROCESSING AUDITS AND PROBLEMS NOTED

Blind audits to verify the accuracy of the dosimetry processing system are used at only two sites. A blind audit consists of processing dosimeters with known doses to assess how accurately the dose equivalent is being determined. A third site regularly processes TLDs with known exposures through the TLD reader to verify that the reader is operating correctly.

Eight of the sites reported an energy response problem for their dosimeters. Only two sites indicated a lack of sensitivity; four reported calibration problems; four reported accuracy problems (occasional "flyers" or inconsistent data); five indicated a gamma interference problem in the interpretation of neutron dose; and four mentioned a track fading problem with NTA film dosimeters. Two sites also reported a need for extremity neutron dos imeters. 


\section{NEUTRON DOSIMETRY: CURRENT PROBLEMS AND AREAS}

\section{FOR IMPROVEMENT AND DEVELOPMENT}

The future of personne 1 neutron dosimetry is uncertain at present. Existing personnel neutron dosimeters are not fully adequate to meet the current needs of workers and the recommendations of regulatory agencies. The National Council on Radiation Protection and Measurements is now examining the risks associated with both high- and low-LET radiations, and may in future lower neutron dose limits or redefine or increase the quality factors for fast neutrons (NCRP 1980). Either change could have two effects: it might increase the number of persons to whom neutron dosimeters would be issued, and it would increase the need for greater accuracy in personnel neutron dosimetry. In the interim, NCRP has recommended that "steps be taken to reduce the potential exposure of individuals who may receive neutron doses that are a substantial fraction of the current maximum permissible dose" (NCRP 1980).

This section presents a summary of the status of personnel neutron dosimetry, together with some suggestions for improvements in existing dosimetry systems and calibration techniques and some discussion of potential future directions in personnel neutron dosimetry. Clearly, increased emphasis should be given to neutron dosimetry research to develop the more accurate dosimeters that may be required in the future.

\section{SUMMARY OF CURRENT PROBLEMS IN NEUTRON DOSIMETRY}

No truly adequate neutron dosimeter is available for use today. The accuracy of personnel neutron dosimetry is poor, as evidence by dosimeter surveys and by dosimeter comparison studies such as that of Plato and Hudson (1979). Many neutron dosimeters do not meet NCRP's recommendations on dosimeter accuracy. Chabot, Jimenez, and Skrable found from their survey (1978) that $45 \%$ of personnel neutron dosimeters were in error by more than $60 \%$. Significant improvements must be made in personne 1 neutron dosimetry if an accuracy comparable to that of gamma dosimetry is to be achieved. 
The neutron dosimeters presently used in the United States -- NTA film and TLD-albedo -- have been in use for over 15 years. Both have an energy response problem. Many TLD-albedo dosimeters that employ a single calibration factor are purposely calibrated to overestimate the dose equivalent to compensate for inaccuracies introduced by the energy response problem. A track etch dosimeter is now commercially available and track etch techniques show promise, but none has yet been introduced at any DOE site.

The introduction of nuclear fusion technology may increase the need to improve neutron dosimetry. If fusion proves to be feasible and large numbers of fusion plants are built for electric power production, the number of persons exposed to neutrons will increase. A problem already exists because increasing numbers of persons are entering neutron fields inside the containment vessels of commercial nuclear power plants while the reactors are operating.

Concern about the effects of low-level radiation is increasing, and more accurate neutron dosimeters may be needed to measure these low levels. At present, neutron dosimeters have a lower detection limit of 1 to 50 mrem under ideal conditions. There is also some evidence that neutrons and other highLET radiations pose a higher degree of hazard than has been assumed in the past (Rossi 1977a and 1977b; Rossi and Mays 1978). If the neutron quality factors currently under study by NCRP are revised, NTA dosimeters will have neither sufficient accuracy nor a low enough detection limit to meet the requirements of NCRP Report No. 57 (1978). TLD-albedo dosimeters may have an adequate lower detection limit, but their severe energy dependence problem must still be resolved.

\section{IMPROVEMENTS IN EXISTING DOSIMETRY}

It may be possible to improve existing dosimetry systems and dosimeter calibrations using techniques that have been successful at several DOE laboratories. These techniques are discussed below for NTA film and TLD-albedo systems. In addition, the accuracy of the entire personnel dosimetry system can be verified by the use of audits. 
Improving NTA Film Dosimetry Systems

NTA film dosimeters are still being used at a few DOE facilities, usually at sites where small numbers of persons are exposed to neutrons and where the expense of converting to automated TLD systems is difficult to justify. Traditionally, NTA film dosimeters are also used at high-energy accelerators that produce neutrons with energies we 11 above the $0.7-\mathrm{MeV}$ energy threshold of NTA film. Thermoluminescence-albedo dosimeters are not used at these sites because of their low sensitivity to very-high-energy neutrons.

Health physicists using NTA film dosimeters are we 11 aware of the problems involved in their use. At high-energy accelerators or other facilities with massive amounts of shielding, periodic surveys are made using instruments that can detect neutrons with energies below the threshold of NTA film. Activation foils or TLD-albedo dosimeters, which almost always indicate the presence of neutrons even if the correct dose equivalent cannot be determined, are often used in conjunction with NTA film as area monitors, to detect the presence of neutrons in occupied areas.

Track fading was mentioned as a problem at four sites that use NTA film dosimeters. This problem might be alleviated by using nitrogen desiccation and sealing the NTA film in a moisture-proof package (Bartlett 1978).

Improvements can also be made in the calibration of NTA film dosimeters, which are often calibrated in free air (without a phantom) using PuBe neutron sources. The neutron energy spectrum for the PuBe source (average neutron energy of $4.5 \mathrm{MeV}$ ) is often quite different from that found in the work locations where the dosimeter is used. Bartlett has reported on correction factors to account for differences in the energy spectra (1978).

Improving Thermoluminescence-Albedo Dos imetry Systems

Thermoluminescence-albedo dosimeters are the most widely used type of personnel neutron dosimeter. They can be automated and are easy to use. They also give a positive response to a significant neutron exposure, particularly for the low-energy neutrons that NTA film dosimeters do not detect. TWO DOE sites have recently converted from NTA film to TLD-albedo systems. 
A wide variety of TLD-albedo dosimeter designs are in use at DOE facilities. The smallest is a TLD-albedo dosimeter containing polyethylene completely surrounded by cadmium (Hankins 1973). This dosimeter can be worn loosely attached to the body at almost any orientation. However, it is not as sensitive as some others. If higher sensitivity and a lower detection limit are required, the neutron dosimeter can be separated from the security credentials and beta-gamma dosimeters with which they are often associated and a dosimeter similar to that described by Hoy (1972) can be used. This dosimeter is one of the largest (up to $6.3 \mathrm{~cm}$ [2.5 in.] square) and is securely positioned on the body by a belt. These dosimeters and others are discussed in deta $i 1$ in Appendix B.

Several techniques can be used to improve the accuracy of existing TLDalbedo systems. The TL chips or disks can be screened to ensure that they a 11 have the same sensitivity. Periodic checks can be made to eliminate TL chips that are broken or contaminated. An automatic hot-gas reader is convenient for screening chips. Thoroughly cleaning the chips in a solvent such as absolute ethanol should alleviate problems caused by dirt, oil, chalk dust, and some cosmetics. (Perfume, which causes erroneous readings when spilled on a dosimeter, cannot be removed by cleaning with absolute ethanol.)

The most important step toward improving the accuracy of TLD-albedo systems is determining the correct calibration factor. The TLD-albedo dosimeter is very sensitive to the energy spectrum of the incident neutrons, especially to the low-energy neutrons resulting from scattering. In many instances, the response of the TLD-albedo dosimeter is influenced more by room-scattered neutrons than by those coming directly from the source. Ideally, the TLD-albedo dosimeter should be calibrated using the same neutron energy spectrum as that encountered in the wcrk locations. Unfortunately, this is not always possible.

There are two basic ways of calibrating TLD-albedo dosimeters: 1) by applying a constant calibration factor for all dosimeters, and 2) by applying a variable calibration factor, the value of which is determined by field 
measurements at work locations. The first method is the simplest to use; the second method is far more accurate but is difficult to use. Each method is discussed below.

A single calibration factor applied to all dosimeters was the first method used at most DOE facilities. However, there is considerable disagreement over how the single calibration factor should be determined. One school of thought maintains that TLD-albedo dosimeters should be calibrated under low-scatter conditions using an unmoderated source, preferably ${ }^{252} \mathrm{Cf}$, to match the fission spectrum usually present from plutonium and plutonium oxide sources. Advocates of this approach state that in work areas, TLD-albedo dosimeters are exposed to low-energy scattered neutrons that cause the dosimeters to overest $i$ mate the actual dose equivalent, perhaps by as much as a factor of two. Under these conditions, TLD-albedo dosimeter results are always conservative.

Others argue that using an unmoderated source is unrealistic and that lowscatter conditions are rarely found in work areas where dosimeters are used. They maintain that TLD-albedo dosimeters should be calibrated using moderated neutron sources, although there is little agreement concerning how much and what type of moderator should be used. The National Bureau of Standards has built a TLD-albedo dosimeter calibration source using ${ }^{252} \mathrm{Cf}$ moderated by $15 \mathrm{~cm}$ ( $5.9 \mathrm{in.}$ ) of deuterium oxide (Schwartz and Eisenhauer 1979).

These arguments may be resolved when neutron spectral measurements are made in work areas and calibrations laboratories and are correlated with the responses of TLD-albedo dosimeters exposed at the same locations. A few correlations have already been made for the unique low-energy spectra found inside the containment vessels of operating nuclear reactors (Hankins and Griffith 1979; Hajna 1 1979). Here the TLD-albedo dosimeters were found to overestimate the neutron dose equivalent by an order of magnitude. Many additional spectral measurements must be made before this issue is resolved.

For the past few years, facilities at the National Bureau of Standards have been made available for the calibration of personnel neutron dosimeters (Schwartz 1977). These facilities, which can be used for determining energy response or a single calibration factor, include the following: 
- a high-yield ${ }^{252} \mathrm{Cf}$ source with a continuous spontaneous fission spectrum

- a thermal neutron beam with a Maxwellian neutron energy spectrum

- monoenergetic neutron beams of 2, 24, and $144 \mathrm{keV}$ produced at the NBS filtered-neutron-beam facility

- monoenergetic neutrons with energies of $100 \mathrm{keV}$ to $1.5 \mathrm{MeV}$ produced by a Van de Graaff accelerator.

In addition, a moderated neutron source has been constructed at NBS for use in calibrating TLD-albedo dosimeters (Schwartz and Eisenhauer 1979). Lawrence Livermore Laboratory has a specially designed calibration and irradiation facility that has spheres of polyethylene, water, deuterium oxide, and aluminum moderators into which ${ }^{252} \mathrm{Cf}$ and PuBe sources can be placed (Elliott 1978). Neutron energy spectra have been measured for these moderated sources. The Pacific Northwest Laboratory also has a calibrations laboratory and accelerator available to produce monoenergetic neutrons. These calibration facilities should be better utilized by DOE contractors. (a)

The second basic way of calibrating TLD-albedo dosimeters is to apply a variable calibration factor to account for the variation in dosimeter response with incident neutron energy. Using a calibration factor that varies depending on where the dosimeter is worn necessitates a record-keeping system, which can be expensive and time consuming to maintain. Three methods can be used to compensate for the energy dependence problem.

The first method, which is used at one DOE site, involves measuring the dose-equivalent rate at work locations using rem meters. The TLD-albedo dosimeter is then calibrated by exposing it on a phantom in the known neutron field at the work location.

The second method involves a survey of work areas to determine an appropriate calibration factor. The thermal neutron flux in a 23-cm-dia (9-in.) sphere of polyethylene and in a 7.6-cm-dia (3-inch) cadmium-covered sphere of

(a) For more information, see the list of contacts in Appendix $A$. 
polyethylene is determined using a $\mathrm{BF}_{3}$ proportional counter and a commercially available survey meter. The effective TLD calibration factor can be determined from the ratio of the responses of the two spheres using Figure 1, which is derived from a graph presented by Griffith et al. (1979, p. 244). A similar method of field measurements is reported by Reil, Scofield, and Woo (1979).

A third method consists of making much more elaborate neutron spectral measurements, using neutron spectrometers such as the Bonner or multisphere spectrometer, to more accurately determine the dosimeter response. Some skill and experience are necessary for effective use of the unfolding codes (LOUHI, BON, etc.) to obtain the neutron spectrum, and a complete set of polyethylene spheres is expensive and heavy.

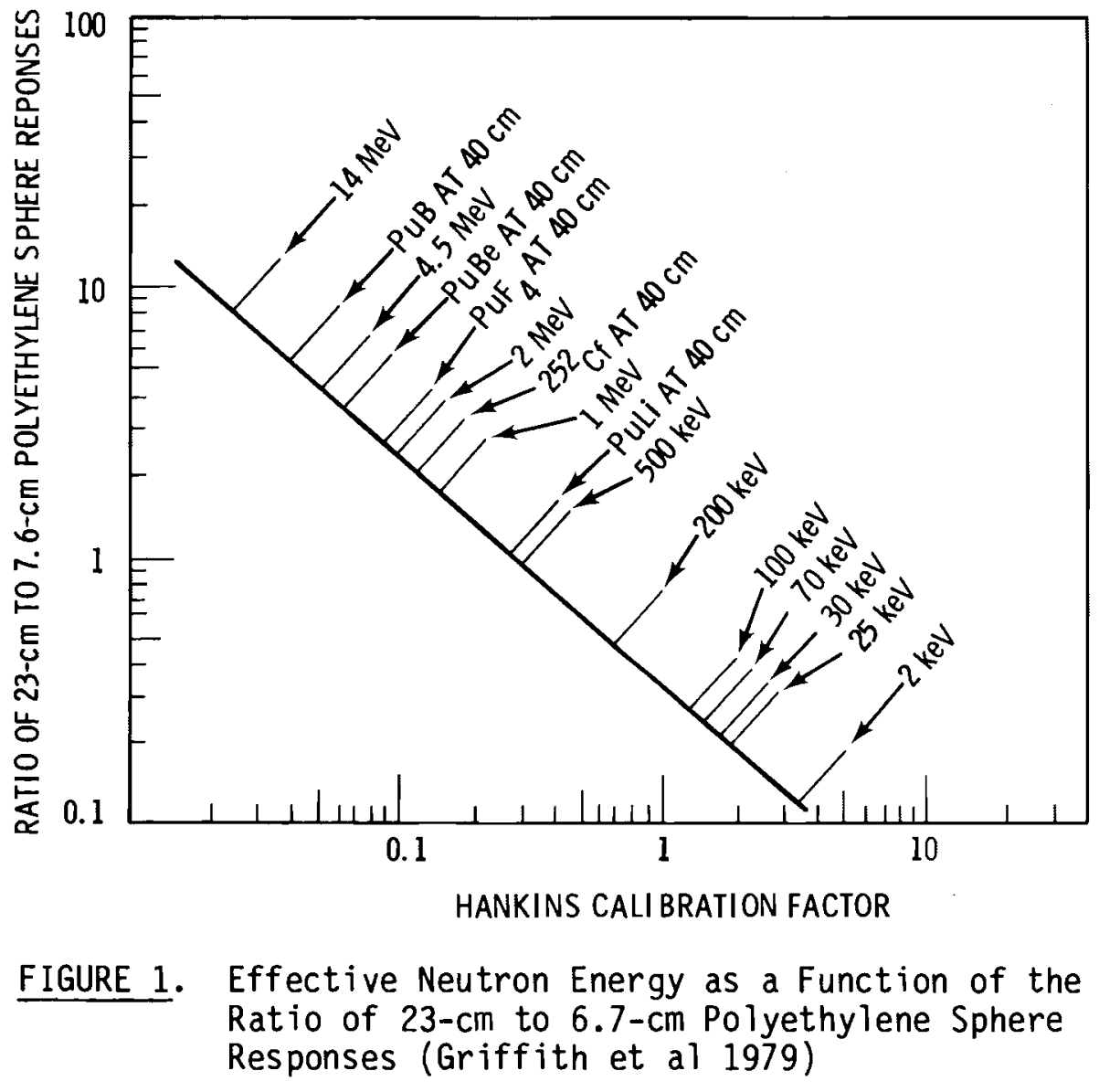


Accuracy Verification Through System Audits

Audits of the dosimetry system, currently used by only three DOE contractors, could be useful at several other sites. Dosimeters with known exposures are introduced into the system and the readings are recorded for imaginary individuals. This is a convenient way to verify the accuracy of the entire dosimetry system, including record keeping; problems can be quickly spotted and steps taken to improve the system if necessary. TwO DOE contractors frequently process TLDs with known exposures through the TLD reader to verify the reader's accuracy.

RECOMMENDATIONS FOR FUTURE PERSONNEL NEUTRON DOSIMETERS

One solution to the energy sensitivity problem of the TLD-albedo dosimeter may be to use it in conjunction with another dosimeter that is more sensitive to higher-energy neutrons (above $100 \mathrm{keV}$ ). This approach has been suggested by others (Griffith, Fisher and Harder 1977; Tymons, Tuyn and Baarli 1973; Distenfeld 1973). Alternatively, new dosimeters can be developed through research on various types of neutron detectors.

Combination TLD-Albedo and Track Etch

Griffith, Fisher and Harder (1977) suggest using TLD-albedo dosimeters to detect low-energy neutrons and track etch dosimeters to detect fast neutrons. The use of electrochemical etching and CR-39 plastic, which has an energy threshold below $200 \mathrm{keV}$, certainly looks attractive. (See Appendix B for more information.) A combination of CR-39 plastic, polycarbonate plastic, and a TLD-albedo system could be used as a crude neutron energy spectrometer for improved accuracy in determining the dose equivalent. Two potential disadvantages to this technique are that 1 ) additional costs are incurred in evaluating an extra dosimeter and 2) the electrochemical etch technique produces tracks that must be counted by hand, so the system is not easily automated. Combination TLD-Albedo and NTA Film

Several sites are using combinations of TLD-albedo and NTA film dosimeters (Anderson and Crain 1977). Unfortunately, this combination introduces the 
problems associated with NTA dosimeters (see Appendix B); however, it may be a convenient way to switch from NTA film dosimeters to another type of combination dosimeter.

Combination TLD-Albedo and Deep-Trap TLD

Perhaps the most easily implemented combination dosimeter would utilize an LiF TLD-albedo dosimeter for detecting low-energy neutrons and a deep-trap TLD that responds directly to fast neutrons (see Appendix B). This approach would probably be the least expensive to put in place, since almost all DOE facilities already use TLDs. The only additional expenses wou:d be for the additional $\mathrm{CaF}_{2}: \mathrm{Tm}(\mathrm{TLD}-300)$ and $\mathrm{CaF}_{2}: \mathrm{Mn}$ (TLD-400) dosimeters and for new microprocessor-controlled TLD readers that would separately read out the $150^{\circ} \mathrm{C}$ and $240^{\circ} \mathrm{C}$ glow peaks of the TLD-300 material. Before this type of system can be used, additional work must be done on improving the sensitivity, examining the energy response, and investigating the fading of the $150^{\circ} \mathrm{C}$ glow peak in TLD-300 material.

\section{Other New Types of Dosimeters}

Additional research needs to be done on other neutron detectors, such as silicon diodes, plastics that exhibit changes in electrical conductivity when exposed to neutrons, plastics that act as semiconductors, electronic devices, electrets, and the superheated drop detector. Information on how these detectors could be used as neutron dosimeters can be found in Appendix $B$. It would be possible to determine the suitability of some of these devices by exposing them to monoenergetic neutrons to determine their energy response and lower limit of detection. Those with desirable characteristics could then be developed further. This research might reveal a new and more accurate personnel neutron dosimeter that would be suitable for future dosimetry needs.

\section{OTHER RECOMMENDATIONS}

At the present time, it is not possible to identify the "best" type of neutron dosimeter for future development. A neutron dosimetry "think tank" should be established to evaluate new types of dosimeters and recommend new 
areas of research. This "think tank" should include DOE and DOE contractor personnel and should consult with representatives from private industry and from other federal agencies, such as NRC and NBS. A spectrum of persons with different backgrounds could provide a broad overall view so as not to overlook some possible new neutron dosimetry techniques. The "think tank" needs to assess current technology and identify future areas for research that are not now being explored. The long-range goal of the "think tank" should be to focus research on a few neutron dosimetry systems, perhaps two to five, for further development.

In the past, research on personnel neutron dosimeters has been somewhat fragmentary. Each DOE site has developed its own neutron dosimetry system specifically tailored to meet the needs of that site. After the personnel dosimeter system is in place, research on personnel neutron dosimeters usually stops, although the needs for neutron dosimetry may change with time. This trend has resulted in a wide diversity of dosimetry systems, some of which are not adequate. Centralized funding for research on personnel neutron dosimeters has not been available for any extended period of time.

To deal with these problems, a "lead laboratory" for research on personnel neutron dosimeters should be established. The lead lavoratory would provide strong technical program management and coordinate dosimeter research, although it would not necessarily conduct the research itself. It would advise DOE, review technical ideas, set priorities, and assist in setting up meetings and dosimeter intercomparison studies. If necessary, the lead laboratory may also provide some dosimeter calibrations in conjunction with NBS. A strong continuing dosimeter research program may result in a more accurate personnel neutron dosimeter design that will be more universally applicable than current designs. 


\section{REFERENCES}

American National Standards Institute. 1976. Personnel Neutron Dosimeters (Neutron Energies Less than $20 \mathrm{MeV}$ ). ANSI N319-1976, New York, New York.

American National Standards Institute. July 1978. Draft American National Standard Criteria for Testing Personnel Dosimetry Performance. ANSI N13.11, New York, New York.

Anderson, M. E., and S. L. Crain. 1977. "A Combination TL-Film Personnel Neutron Dosimeter." In Sixth ERDA Workshop on Personnel Neutron Dosimetry. PNL-2449, Pacific Northwest Laboratory, Richland, Washington.

Bartlett, W. T. 1978. "Personnel Neutron Monitoring at NRPB." In Seventh DOE Workshop on Personnel Neutron Dosimetry. PNL-2807, Pac if ic Northwest Laboratory, Richland, Washington.

Barton, T. P., and C. E. Easterly. 1979. Neutron Personnel Dosimetry Considerations for Fusion Reactors. ORNL/TM-6756, Oak Ridge National Laboratory, Oak Ridge, Tennessee.

Caswell, R. S., L. J. Goodman and R. D. Colvett. 1975. "International Intercomparison of Neutron Dosimetry." In Radiation Research: Biomedical, Chemical and Physical Perspectives, ed. D. F. Nygaard. Academic Press, New York.

Chabot, G. E., M. A. Jimenez and K. W. Skrable. 1978. "Personnel Dosimetry in the USA." Health Phys. 34:311.

Code of Federal Regulations. Title 10, Part 20, Sec. 20.202, "Personnel

Dickson, H. W. 1980. Fourth Personnel Dosimetry Intercomparison Study. ORNL/TM-7134, Oak Ridge National Laboratory, Oak Ridge, Tennessee.

Distenfeld, C. H. 1973. "Summary of Personnel Neutron Dosimetry Development at Brookhaven National Laboratory." In Fourth AEC Workshop on Personnel Neutron Dosimetry. BNWL-1717, Pacif ic Northwest Laboratory, Richland, Washington.

Elliott, J. H. 1978. Tour of the Standards and Calibrations Laboratory. UCRL-52537, Lawrence Livermore Laboratory, University of California, Livermore, California.

Gilley, L. W., and H. W. Dickson. 1979. Third Personnel Dosimetry Intercomparison Study. ORNL/TM-6114, Oak Ridge National Laboratory, Oak Ridge, Tennessee. 
Gilley, L. W., H. W. Dickson and D. J. Christian. 1976. 1976 Intercomparison of Personnel Dosimeters. ORNL/TM-5672, Oak Ridge Nationa T Laboratory, Oak Ridge, Tennessee.

Goodman, L. J. 1976. "Nonparametric Analysis of International Neutron Dosimetry Intercomparison." In Neutron Dosimetry Workshop, Rijswijk, Nether lands. CONF-760533-2, National Technical Information Service, Springfield, Virginia.

Griffith, R. V., J. C. Fisher and C. A. Harder. 1977. Development of a Combined Etch Track-Albedo Dosimeter. UCRL-50007-77-1, Lawrence Livermore Laboratory, University of California, Livermore, California.

Griffith, R. V., D. E. Hankins, R. B. Gammage, L. Tommasino and R. V. Wheeler. 1979. "Recent Developments in Personnel Neutron Dosimeters - A Review." Health Phys. 36:235-260.

Hajnal, F. 1979. Stray Neutron Fields Inside the Containment of PWR's. IAEA-SM-242/24, International Atomic Energy Agency, Vienna, Austria.

Hankins, D. E. 1973. A Small, Inexpensive Albedo-Neutron Dosimeter. LA-5261, Los Alamos Scient ific Laboratory, Los Alamos, New Mexico.

Hankins, D. E. 1975. "The Effect of Energy Dependence on the Evaluations of Albedo Neutron Dosimeters." In Proceedings of the Ninth Midyear Topical Symposium. Health Physics Society, Denver, Colorado.

Hankins, D. E. 1979. Phantoms for Calibrating Albedo Neutron Dosimters. UCRL-82897, Lawrence Livermore Laboratory, University of California, Livermore, California.

Hankins, D. E., and R. V. Griffith. 1979. "A Survey of Neutrons Inside the Containment of a Pressurized Water Reactor." In Radiation Streaming in Power Reactors. ORNL/RSIC-43, Oak Ridge National Laboratory, Oak Ridge, Tennessee.

Hoy, J. E. 1972. Personnel Albedo Neutron Dosimeter with Thermoluminescent $6 \mathrm{Li}$ and $7 \mathrm{LiF}$. DP-1277, E. I. du Pont de Nemours and Company, Inc., Savannah River Plant, Aiken, South Carolina.

National Council on Radiation Protection and Measurements. 1971. Protection Against Neutron Radiation. NCRP Report No. 38, Washington, D.C.

National Council on Radiation Protection and Measurements. 1978. Instrumentation and Monitoring Methods for Radiation Protection. NCRP Report No. 57, Washington, D.C. 
National Council on Radiation Protection and Measurements. 1980. "NCRP Statement on Dose Limit for Neutrons." Washington, D.C.

Nuclear News. 1980. Review article, no author. "Lower Exposure Limits." Nuclear News 23(1):36.

Plato, P., and G. Hudson. 1979. Performance Testing of Personnel Dosimetry Services. NUREG/CR-1064, U.S. Nuclear Regulatory Commission, Washington, D.C.

Reil, G., N. Scofield and K. Woo. 1979. "Measurements to Determine Field Calibrations for an Albedo Neutron Dosimeter." In Abstracts of the Twenty-Fourth Annual Meeting of the Health Physics Society, Philadelphia, Pennsylvania. Health Physics Society, Denver, Colorado.

Rhoades, W. A., and F. R. Mynatt. 1973. DOT-III Two Dimensional Discrete Ordinance Transport Code. ORNL/TM-4280, Oak Ridge National Laboratory, Oak Ridge, Tennessee.

Rossi, H. H. 1977a. "The Effects of Small Doses of Ionizing Radiation: Fundamental Biophysical Characteristics." Radiat. Res. 71:1-8.

Rossi, H. H. 1977b. "A Proposal for Revision of the Quality Factor." Radia. Environ. Biophys. 14(4):275.

Rossi, H. H., and C. W. Mays. 1978. "Leukemia Risk from Neutrons." Health Phys. 34:353-360.

Schraube, H., and H. G. Paretzke. 1976. "Neutron Fluence Measurements with Track Detectors: Preliminary Results of INF IT." In Ninth International Conference on Solid State Nuclear Track Detectors, Neuherberg/Munchen. CONF-760964-18, National Technical Information Service, Springfield, Virginia.

Schwartz, R. B. 1977. "Personnel Neutron Dosimeter Calibration Facilities at the National Bureau of Standards." In Sixth ERDA Workshop on Personnel Neutron Dosimetry. PNL-2449, Pac if ic Northwest Laboratory, Richland, Washington.

Schwartz, R. B., and C. M. Eisenhauer. 1979. The Design and Construction of D, 0 -Moderated $252 \mathrm{Cf}$ Source for Calibrat ing Neutron Personnel Dosimeters Used at Nuclear Power Plants. NUREG/CR-1204, U.S. Nuclear Regulatory Commission, Washington, D.C.

Sims, C. S. 1980. Fifth Personnel Dosimetry Intercomparison Study. ORNL/TM-7155, Oak Ridge Nationa T Laboratory, Oak Ridge, Tennesee. 
Tymons, B. J., J.W. N. Tuyn and J. Baarii. 1973. "System for Personnel Dosimetry in Mixed Radiation Fields." In Volume 2 of Neutron Monitoring for Radiation Protection Purposes: Proceedings of a symposium. International Atomic Energy Agency, Vienna, Austria.

U.S. Department of Energy. 1978. "Standards for Radiation Protection." In DOE Manual, Chapter 0524. Washington, D.C.

U.S. Nuclear Regulatory Commission. 1980. "Personnel Neutron Dosimeters." Regulatory Guide 8.14, Washington, D.C. 


\section{APPENDIX A}

CONTACTS FOR FURTHER INFORMATION 
APPENDIX A

CONTACTS FOR FURTHER INFORMATION

For information on the following topics, contact the persons listed below.

- DOE Neutron Dosimetry Worshops:

Edward J. Vallario

Assistant Chief/Manager

Health Physics Programs

Division of Operational and Environmental Safety

U.S. Department of Energy

Washington, DC 20545

FTS $233-5640$

- Personnel dosimeter intercomparsion studies:

Howard W. Dickson or C. S. Sims

Health and Safety Research Division

Oak Ridge National Laboratory

Oak Ridge, TN 37830

(615) $574-5860$ or (615) $574-5851$

FTS $624-5860$ or $624-5851$

- National Bureau of Standards calibration facilities:

Dr. Robert B. Schwartz

Reactor Building 235

U.S. Department of Commerce

National Bureau of Standards

Washington, DC 20234

FTS $921-2421$

- Lawrence Livermore Laboratory calibration facilities:

Jack Elliott

University of California

Lawrence Livermore Laboratory

P.0. Box 808

Livermore, CA 94550

FTS 532-5225 
- Pacific Northwest Laboratory calibration facilities:

Craig Yoder

Battelle, Pacific Northwest Laboratories

Richland, WA 99352

FTS $444-4366$ 
APPENDIX B

TYPES OF NEUTRON DOSIMETERS 


\section{CONTENTS}

TYPES OF NEUTRON DOSIMETERS .

NUCLEAR TRACK EMULSION (NTA FILM) DOSIMETERS $\quad . \quad . \quad . \quad$. B.3

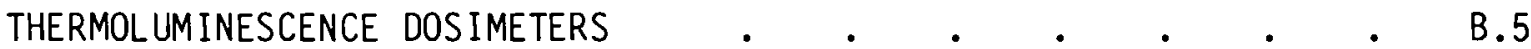

Thermo luminescence-Albedo Dosimeters . $\quad$. $\quad$. $\quad$ B.5

Hydrogeneous Radiatior TLDs . . . . . . . B.12

LET-Dependent Glow Peaks - Deep-Trap TLDs . . . . B.13

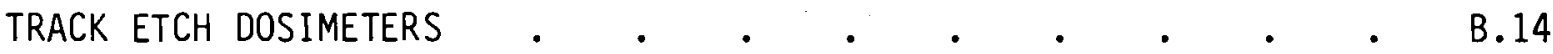

Fission Track Etch Dosimeters . . . . . . . . B.15

Recoil Track Etch Dosimeters . . . . . . . B.18

Track Counting Techniques . . . . . . . . . B.19

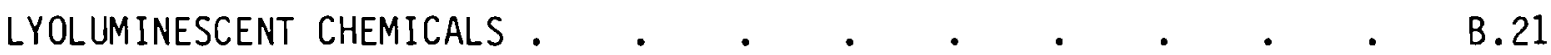

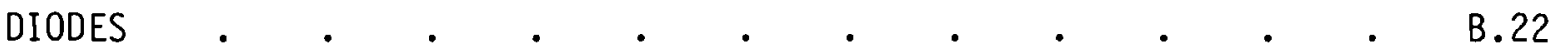

DEVICES USING ELECTRICAL CONDUCTIVITY IN PLASTICS $\quad . \quad$ • $\quad$ B.23

THERMALLY STIMULATED EXOELECTRON EMISSION (TSEE) DEVICES • • B. B

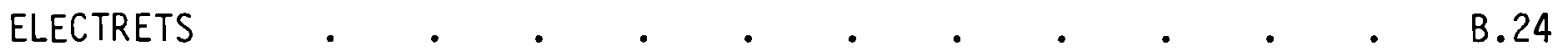

ELECTRONIC DEVICES

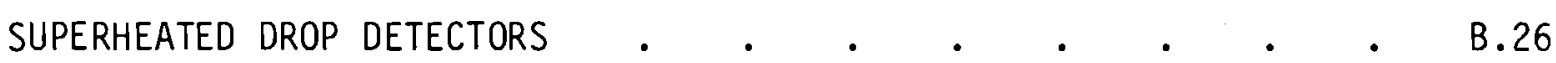

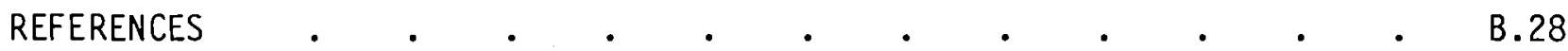




\section{FIGURES}

B.1 Basic Concept of TLD-Albedo Dosimeter . . . . . . . . . B.6

B.2 Energy Dependence of Various Albedo Dosimeters . . . . . . B.9

B.3 Design of Karlsruhe TLD-Albedo Dosimeter . . . . . . . B.10

B.4 Schematic Representation of TLD-Albedo Dosimeters

Used at DOE Facilities . . . . . . . . . . . . B.12

B.5 Energy Response of Fission Fragment Track Dosimeter Compared with Fission Cross Sections . . . . . . . . B.16

B.6 Fission Cross Sections for $232 \mathrm{Th}$ and $237 \mathrm{~Np}$ Compared with the ICRP Dose Equivalent Per Unit Fluence . . . . . B.18

B.7 Measured Neutron Energy Response of Electro-Chemically Etched Polycarbonate and CR-39 Plastics . . . . . . . B.20 
APPENDIX B

\section{TYPES OF NEUTRON DOSIMETERS}

The various types of neutron detectors that are currently used or have the potential for use as personnel neutron dosimeters are discussed below. They include:

- nuclear track emulsion (NTA) dosimeters

- thermoluminescence dosimeters (TLDS)

- track etch dosimeters, including those using fissionable foils and those in which fast neutrons interact directly with a plastic

- lyoluminescent chemicals

- diodes

- devices using electrical conductivity in plastics

- thermally stimulated exoelectron emission devices

- electrets

- electronic devices

- superheated drop detectors.

For a comparison of these devices' characteristics with the characteristics of an "ideal" personnel neutron dosimeter, refer to Tables 1 to 4 in the main text.

NUCLEAR TRACK EMULSION (NTA FILM) DOSIMETERS

The oldest type of dosimeter still in use at DOE facilities is the nuclear track emulsion (NTA film) dosimeter, which consists of a thin layer of emulsion on a plastic base. Neutrons interact with hydrogen in the dosimeter to produce tracks in the emulsion, which are made visible by developing the film. The neutron dose equivalent is calculated by counting the tracks with a microscope or other optical device. 
The main advantages of the NTA film dosimeter are that the film is inexpensive and responds to high-energy neutrons. However, NTA film also suffers from several disadvantages. One of the first problems recognized was track or latent image fading caused by oxidation by atmospheric oxygen in the presence of water vapor (Albuoy and Faraggi 1949; Knight 1974; Sayed and Piesch 1974; Becker 1973). The amount of fading can be reduced by sealing the NTA film in mo isture-proof packages with or without desiccants. It is possible to almost eliminate fading by using nitrogen desiccation and sealing the film in mo isture-proof pouches (Bartlett 1978). Another technique for handling the problem of fading is to expose calibration films to the same environmental conditions as the field dosimeters, so that similar amounts of fading occur.

If track fading is controlled, the major disadvantages of NTA film are its energy response and statistical problems at low neutron doses. The NTA film dosimeter is sensitive to fast neutrons above about $0.7 \mathrm{MeV}$. This lowenergy threshold varies somewhat depending upon the criterion used for determining what constitutes a proton recoil track. The response (tracks/rem) varies by a factor of three from $0.7 \mathrm{MeV}$ to $14 \mathrm{MeV}$ (Barton and Easterly 1979). Nuclear track emulsion film is also sensitive to thermal neutrons, which interact with nitrogen in the emulsion to produce protons by an $N(n, p)$ reaction. On a dose-equivalent basis, the NTA dosimeter has about the same sensitivity to 15-MeV neutrons and thermal neutrons (Bartlett 1978). At low neutron exposures, the statistical accuracy of NTA film is poor -- few tracks are produced for dose equivalents in the millirem range.

There are several other disadvantages of NTA film dosimeters. High temperatures darken the film so that the tracks cannot be read (e.g., if someone leaves a dosimeter in a parked car exposed to the sun). About 1 rem of lowenergy photons can also darken the film to the point where tracks cannot be counted. In addition, optically counting the proton recoil tracks can be tedious work. It may be possible to automate the track-reading process, but this change would be very expensive. 
Nuclear track emulsion dosimeters are still used at six DOE sites, usually where few dosimeters are issued and high-energy neutrons are present.

\section{THERMOLUMINESCENCE DOSIMETERS}

Thermoluminescence dosimeters (TLDs) emit light after being irradiated by ionizing radiation. This phenomenon occurs in many minerals found in nature. For neutron dosimetry, special phosphors containing lithium or boron are made. The lithium or boron absorbs neutrons and produces charged particles that interact with the phosphor.

This section deals with three types of thermoluminescence dosimeters: TLD-albedo dosimeters, in which low-energy neutrons reflected from the body interact with the TL chips; hydrogenous radiator TLDs, in which neutrons interact with hydrogen to produce charged particles that activate the TL chips; and deep-trap TLDs, in which fast neutrons interact directly with the phosphor to produce an enhanced glow peak upon readout.

Thermoluminescence-Albedo Dosimeters

The dosimeter most widely used at DOE facilities is the TLD-albedo dosimeter, which uses the ${ }^{6} i(n, \alpha)^{3} H$ reaction in thermoluminescent materials to detect neutrons. Thermoluminescence-albedo dosimeters are worn on the body. Incident fast neutrons enter the body and are moderated, and slow neutrons are reflected back to the dosimeter (hence the term albedo, from the reflected neutrons). Slow neutrons interact with the thermoluminescent material, usually through ${ }^{6} \mathrm{Li}(n, \alpha)^{3} \mathrm{H}$ rections, and the charged particles excite the thermoluminescent material. When heated, the phosphor emits light in quantities proportional to the energy deposited in the material.

The thermoluminescent material is sensitive to both neutrons and photons, so a correction must be made for gamma exposures by using matched pairs of TL chips. One pair is made from ${ }^{6} \mathrm{LiF}$, which detects neutrons and photons, and the other is made from fully enriched ${ }^{2} \mathrm{LiF}$, which detects mostly photons. The neutron response is found by subtracting the ${ }^{7} \mathrm{LiF}$ response from the ${ }^{6} \mathrm{LiF}$ response. 
The basic concepts of the TLD-albedo dosimeter are shown in Figure B.1. Pairs of ${ }^{6}$ iF and ${ }^{7} L i F$ TL chips are placed on each side of a cadmium shield, which is used to differentiate incident thermal neutrons from the albedo neutrons reflected from the body. The top pair measure the incident tinermal neutron dose; the bottom pair measure the albedo neutrons from which the incident fast neutron dose is inferred. The cadmium ioil is usually between 0.4 and $1.5 \mathrm{~mm}(0.015$ and $0.060 \mathrm{in.})$ thick. Thinner foils allow too many thermal neutrons to pass through. The cadmium foil should be as large as practical to prevent thermal neutrons from diffusing around the foil to the bottom TL chips; the smallest useful diameter for the cadmium foil is about $1 \mathrm{~cm}(0.39$ in.) (Hankins 1972). Cadmium emits gamma rays when it captures a neutron, so gamma shields are sometimes placed between the cadmium and the TL chips. Boron or boron-loaded plastic can also be used in place of cadmium, but a much thicker shield is required because of boron's lower absorption cross section. The material is often enriched in ${ }^{10} \mathrm{~B}$, but this is expensive.

The TLD-albedo dosimeter must be worn close to the body to function properly. As it is moved away from the body, its sensitivity to fast neutrons decreases and its sensitivity to thermal neutrons increases. The common practice of wearing a dosimeter loosely clipped on a pocket containing a pack of cigarettes can cause inaccurate readings. Some TLD-albedo dosimeters will not

INCIDENT NEUTRONS

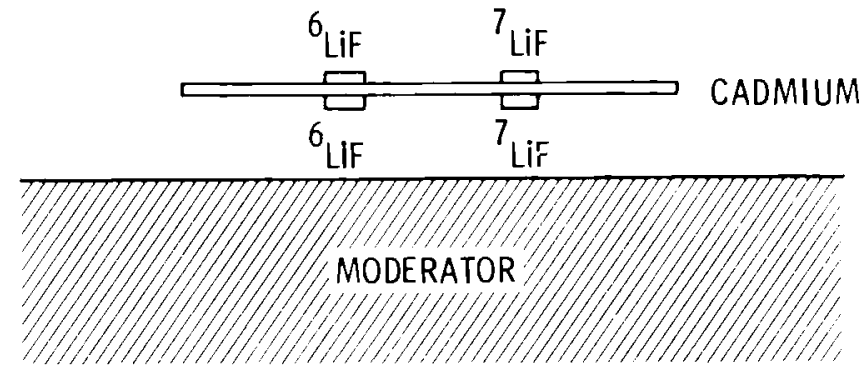

FIGURE B.1. Basic Concept of TLD-Albedo Dosimeter 
function at all if they are worn backwards clipped to the inside of a pocket or loosely held on a necklace. Hankins has developed a symmetric dosimeter that can be worn in either direction (Hankins 1973). It also contains a polyethylene moderator inside the cadmium shield, so it does not have to be worn next to the body to respond to neutrons.

Advantages and Disadvantages of Thermoluminescence-Albedo Dosimeters

There are several advantages to TLD-albedo dosimeters:

1. They always give some indication when exposed to a significant neutron dose.

2. They are relatively inexpensive and can be reused over and over.

3. They are easily fabricated and are usually lightweight and easy to wear.

4. Readout is simple and can be automated. It is possible to process several thousand dosimeters with relative ease.

5. They are insensitive to humidity and moderate mechanical shock.

Unfortunately, there are also several disadvantages to using TLD-albedo dosimeters:

1. The single most important disadvantage of TLD-albedo dosimeters is that their sensitivity is highly dependent upon the energy of the incident neutron. The dose equivalent indicated by the dosimeter can be in error by an order of magnitude if the dosimeter is not properly calibrated.

2. The TLD-albedo dosimeter is also gamma sensitive. In mixed radiation fields, care must be taken to properly subtract out the photon response of the ${ }^{6}$ LiF chip.

3. Many TLD-albedo dosimeters must be worn properly (i.e., close to the body) or serious errors can result. To overcome this difficulty, some dosimeters are worn on belts or in special pockets sewn into protective clothing. 
4. Most TLD-albedo dosimeters worn flat against the body exhibit some angular dependence, but the effect is small compared to that for $\gamma-\beta$ dosimeters. The hemispherical design used at the Savannah River laboratory seems to overcome some of these problems (Korba and Hoy 1969).

5. Thermoluminescence dosimeters do not give a permanent record, as film or track etch dosimeters do. If the TLD reader malfunctions, the reading may be lost.

6. Thermoluminescence dosimeters must be carefully annealed to preserve the accuracy of their calibration.

7. Some TLDs exhibit fading. The rapid fading problem in TLD-600s and TLD-700s can be overcome by waiting 1 day before reading the TLDs out. High temperatures cause fading problems; $20 \%$ to $40 \%$ fading of TLDs has been found for dosimeters left on the dashboard of cars in the sun.

Energy Response Problems of Thermoluminescence-Albedo Dosimeters

Thermoluminescence-albedo dosimeters have a severe energy response problem, as demonstrated in Figure B.2. A simplistic explanation of this variation in the response to neutrons of various energies is that the mean free path for high-energy neutrons is greater than that for low-energy neutrons, and the fast neutrons penetrate farther into the body before interacting and becoming thermalized. The thermal neutrons must then migrate a farther distance back to the surface of the body, and many are absorbed before reaching the TLDs on the surface. Thus the sensitivity of the TLD-albedo dosimeter decreases with increasing neutron energy.

Several methods can be used to overcome the energy dependence problem. First, TLD-albedo dosimeters can be used in facilities in which the neutron energy spectrum is almost constant. Second, the TLD-albedo dosimeter can be designed to compensate for spectral differences. However, this solution is 


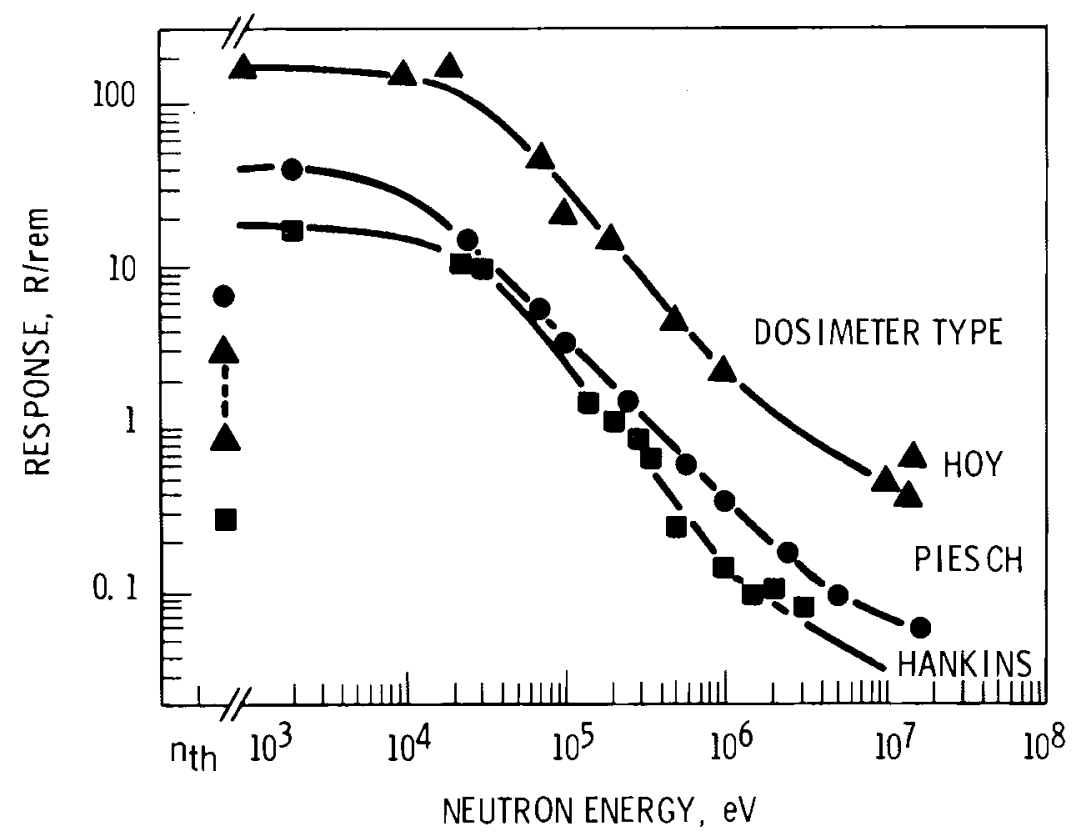

FIGURE B.2. Energy Dependence of Various Albedo Dosimeters (Piesch and Burgkhardt 1978b)

difficult to achieve in practice. Figure B.3 shows a schematic diagram of the Karlsruhe dosimeter (Piesch and Burgkhardt 1978a), a multicomponent dosimeter that provides information about variations in the neutron energy spectrum in work areas. The Karlsruhe dosimeter uses three pairs of TL chips inside a capsule of boron-loaded plastic, which is held to the body by a belt worn about the waist. One of the front chips, designated "a" in Figure B.3, measures the incident thermal neutrons; a middle chip, designated " $m$ ", measures mostly epithermal neutrons; and a bottom chip closest to the body, designated " $i$ ", measures mostly albedo neutrons. The use of the dosimeter to analyze the incident neutron spectrum is described in two papers (Piesch and Burgkhardt 1978a and 1978b). The dosimeter must be calibrated in work areas where it is worn, not in laboratories or by monoenergetic neutron exposures. Piesch introduces a method by which the dose equivalent can be separated into fractions corresponding to thermal and fast neutrons with an effective average energy, which can be related to field measurements and the ratio i/a of the 


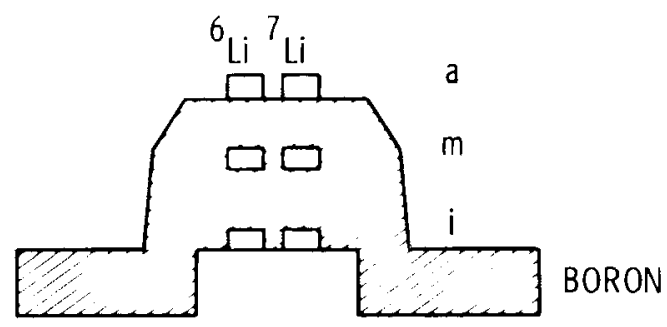

FIGURE B.3. Design of Kar Isruhe TLD-Albedo Dosimeter (Piesch and Burgkhardt 1978a)

responses of the TL chips (Piesch and Burgkhardt 1978a). In this way, Piesch corrects for the TLD-albedo dosimeter's greater response to the low-energy neutrons (thermal and intermediate energies) that result from the high-scatter situations typical of work locations.

A third method of correcting for energy response (Hankins 1975) uses the ratio of the thermal neutron flux inside a $23-\mathrm{cm}$-dia (9-in.-dia) spherical "rem meter" to the flux inside a 7.6-cm-dia (3-in.-dia) sphere covered with a $0.025-\mathrm{cm}(0.010-\mathrm{in}$.$) layer of cadmium. Measurements are usually made with a$ small $\mathrm{BF}_{3}$ counter inside the polyethylene spheres, and a calibration factor is determined from the ratio of the spheres' responses, using a graph similar to that shown in Figure 1 of the main text. The calibration factor will vary depending upon the sensitivity of the ${ }^{6} \mathrm{LiF} T \mathrm{~L}$ chips and the type of albedo dosimeter used, but the data will plot out to a straight line and have the same slope on log-log graphs. This method can be somewhat cumbersome because measurements must be made at several work locations and records kept of which dosimeters were used at these work locations. In many instances, the calibration factors for a single facility may not vary by more than $20 \%$ to $30 \%$ (Hankins 1975). Somewhat similar calibration factors have been obtained using the ratio of Bonner sphere measurements. The ratio of $30-\mathrm{cm}$ to $5-\mathrm{cm}(12-\mathrm{in}$. to 2-in.) spheres has been used (Piesch and Burgkhardt 1978b), as has the ratio of $25-\mathrm{cm}$ to $7.6 \mathrm{-cm}$ (10-in. to 3-in.) spheres (Anderson and Crain 1977). 
Final1y, TLD-albedo dosimeters can be exposed on phantoms in work locations where the dose equivalent or neutron spectrum has been measured to determine the calibration factors. This method is useful in facilities where the spectrum does not change much, and is currently used at three DOE facilities.

\section{Thermoluminescence-Albedo Dosimeters Used at DOE Facilities}

Some typical TLD-albedo dosimeter designs used at DOE facilities are shown schematically in Figure B.4. Figure B.4 (A) shows the design used at Hanford (Kocher et a1: 1971; Endres 1971), in which four or five TL chips are held on a card between teflon films, which can be read out in an automatic TLD reader. All three of the TL chips used in the albedo portion of the badge are shielded with tin, which has a very low neutron cross section, to reduce the photon response of the TLDs. The dosimeter holder also holds a security credential and is worn loosely on the clothing above the waist. This practice often results in problems, since the dosimeter is not always next to the body.

Figure B.4 (B) shows the dosimeter used at the Savannah River Laboratory (Korba and Hoy 1969; Hoy 1972). This design uses a 5.1-cm-dia (2-in.-dia) polyethylene hemisphere to increase its sensitivity, and can be used to measure as little as 5 mrem of fast neutrons. The Hoy dosimeter is worn close to the body on a belt to help ensure accuracy. This design gives high sensitivity, good angular response characteristics, and better precision of measurement than many other designs.

Figure B.4 (C) shows the dosimeter used at the LoS Alamos Scientific Laboratory (Blackstock et al. 1978), which is a modified version of the Hankins dosimeter (Hankins 1973). This dosimeter is symmetric and can be worn frontwards or backwards, and it does not need to be held in contact with the body. However, having cadmium completely surrounding the TL chips does reduce the dosimeter's sensitivity. The TL chips in this dosimeter are held by teflon tape in holes in an aluminum dosimeter card inside the cadmium box. These cards can be easily processed through an automated TLD reader. One advantage of the LASL design is its ability to correct for the energy dependence of the TLD-albedo dosimeter using a calibration factor determined by measurements 


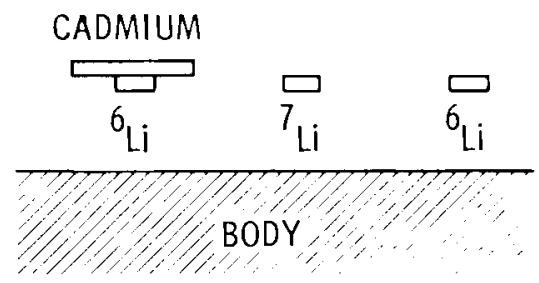

A. HANFORD DOSIMETER

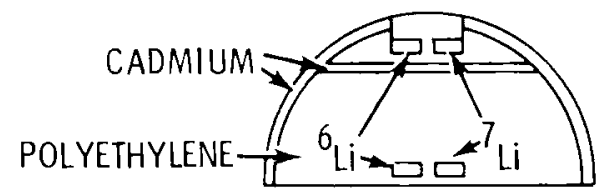

BODY

B. SRL DOSIMETER

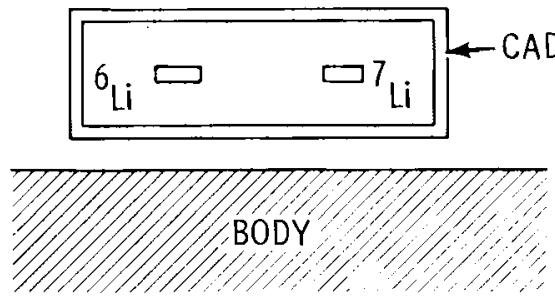

C. LASL DOSIMETER

FIGURE B.4. Schematic Representation of TLD-Albedo Dosimeters Used at DOE Facilities

made with polyethylene spheres at work locations, as described earlier. The Los Alamos design includes provisions for a "piggy back" NTA film dosimeter that clips on to the TLD-albedo dosimeter.

Hydrogeneous Radiator TLDs

Thermoluminescence dosimeters can respond to fast-neutron-induced proton recoils from hydrogenous materials. One can simply mix thermoluminescent powder with a suitable hydrogenous compound. About 15 years ago, G.W.R. Endres mixed ${ }^{6}$ LiF powder with ethanol and was able to detect fast neutrons, but the method was not sensitive enough to be practical. Rzyski, Watanabe and Suntga (1977) used $\mathrm{CaF}_{2}$ mixed with sugar and other organic compounds, which 
detected as little as $10 \mathrm{mrad}$ of fast neutrons from an AmBe source. Considerable effort was required to wash the sugar from the TLD and carefully dry the material.

Another possibility is to permanently mix thermoluminescent materials with a hydrogenous material that has a high melting point. Many thermoluminescent materials are read out at $200^{\circ}$ to $250^{\circ} \mathrm{C}$, so the hydrogenous material must be stable above these temperatures. Parasexiphenyl (melting point $465^{\circ} \mathrm{C}$ ) has been used with $\mathrm{CaSO}_{4}: \mathrm{Dy}$ or $\mathrm{CaSO}_{4}: \mathrm{Tm}$ powder (Becker, Tham and Haywood 1973, p. 584; Becker et al. 1975), but this technique still needs improvement to be useful. Another possibility is the use of lithium hydride, but this may present problems because of its chemical reactivity. An article by Griffith et al. (1979) describes several other hydrogenous radiator techniques. These techniques have demonstrated that thermoluminescent materials mixed with hydrogenous materials do detect fast neutrons, but the sensitivity needs to be improved by an order of magnitude before they will be useful for personnel neutron dosimetry.

\section{LET-Dependent Glow Peaks - Deep-Trap TLDS}

It is possible for fast neutrons to interact directly with thermoluminescent material (Endres 1975). Calcium fluoride doped with thulium, $\mathrm{CaF}_{2}: \mathrm{Tm}$ (TLD-300), produces two glow peaks, one at $150^{\circ} \mathrm{C}$ and one at $240^{\circ} \mathrm{C}$. The hightemperature glow peak shows a direct response to fast neutrons or other highLET radiations, as well as gamma rays. (a) In a gamma field, the ratio of the $150^{\circ} \mathrm{C}$ peak to the $240^{\circ} \mathrm{C}$ peak is 2 to 1 ; in a high-energy neutron field, this ratio becomes almost 1 to 1 . Inconsistent results in early studies were

(a) According to one theory for thermoluminescence in crystalline lattices, impurity atoms in the lattice cause energy levels or energy states called traps, which have energies slightly less than that of a conduction band. Heating the crystal supplies enough energy for electrons to vacate these traps and escape to the conduction band. Electrons repopulating the traps produce the emission of light (luminescence). Some of the energy levels are farther removed from the conduction band than others and require more energy, i.e., higher temperatures, for the electrons to escape. These are the so-called deep-trap energy levels. The electron population of these levels seems to be dependent on the LET of the ionizing radiation striking the crystal. 
traced to fading of the $150^{\circ} \mathrm{C}$ peak. This problem can be eliminated by using $\mathrm{CaF}_{2}: \mathrm{Mn}$ (TLD-400) to determine the gamma dose, since TLD-400s do not exhibit the fast fading that is characteristic of TLD-300s.

Further studies on optimizing the phosphor have been made by Lucas and Kapsar (Lucas and Kapsar 1977; Kapsar and Lucas 1977). At present, it is possible to detect about 1 mrad of fast neutrons from AmBe. There is sufficient precision to determine the total dose within 10\%. Using this glow peak technique to measure fast neutrons directly, in conjunction with a TLD-albedo dosimeter to measure lower-energy neutrons, it may be possible to develop a more accurate neutron dosimeter that could be processed by automated TLD readers being introduced commercially. Lucas and Kapsar (1977) estimated that it would be possible to use this differential glow peak technique for routine personnel neutron dosimetry if the sensitivity could be increased by a factor of three. This increase may be possible using recently developed computercontrolled TLD readers to determine the areas under each glow peak and using $\mathrm{CaF}: \mathrm{Mn}$ to compensate for the gamria fading problem in the $150^{\circ} \mathrm{C} \mathrm{glow}$ peak. Further research should be performed in this area.

\section{TRACK ETCH DOSIMETERS}

Track etch detectors can also be used to determine neutron doses. This technique is currently being studied by more investigators than any other dosimetry method, perhaps because of its simplicity. Griffith has published reviews of the techniques used (Griffith 1974; Griffith et al. 1979). A journal, Nuclear Track Detection, was started recently because of the great interest in track etch techniques.

When charged particles pass through insulators, they produce damaged areas that can be preferentially etched by a suitable solvent to produce a track that is readily visible under a microscope or microfiche reader. The charged particles can be produced by neutrons interacting to produce charged particles in an adjacent foil or by neutron interactions in the material itself. These methods will be discussed below. 


\section{Fission Track Etch Dosimeters}

The use of fissionable foils placed next to a track detector was first proposed by Price, Walker and Fleischer at the General Electric Research Laboratories, Schenectady, New York (Price and Walker, 1963; Walker, Price and Fle ischer 1963; Fleischer, Price and Walker 1965). They used uranium foils to produce fission fragments, which were detected by mica sheets placed next to the foil. The fission fragment tracks were made visible by etching the mica or glass with hydrofluoric acid. Price, Walker and Fleischer found that polycarbonate plastic films (Lexan $($ ) etched by sodium hydroxide or potassium hydroxide solutions were more suitable than the materials originally used. Later, a neutron detector was developed by Baumgartner and Brackenbush (1966) using thin foils of ${ }^{235} \mathrm{U},{ }^{238} \mathrm{U}$, and ${ }^{237} \mathrm{NpO}_{2}$ next to polycarbonate plastic film. The plotted energy response of these fission track detectors follows the fission cross section, as shown in Figure B.5. These devices were found to measure the fast neutron dose to within about $15 \%$ when compared to doses calculated from fluence and spectral measurements. The dosimeters have been used on ly as area monitors at the Hanford site because of prohibitions against people wearing devices containing special nuclear materials. Recently, however, the U.S. Nuclear Regulatory Commission ruled in NUREG-0137 that thorium is exempt from nuclear materials accountability when used in fission foil dosimeters (U.S. NRC 1977).

Many other investigators have used fission fragment track detectors for neutron dosimeters. (a) In 1976, an International Conference on Solid State Nuclear Track Detectors was held at Neuherberg, Federal Republic of Germany, to discuss this type of detector (European Organization for Nuclear Research 1976). Fission fragment track detectors are being used in Europe (Gibson 1978; Harrison 1978).

(B) Registered trademark of General Electric Corporation.

(a) Burger, Griinauer and Paretzke 1971; Cross and Tommasino 1970; Cross and Ing 1975; Distenfeld 1973; Gomma and Hossil 1971; Petre 1973; Yule 1973. 

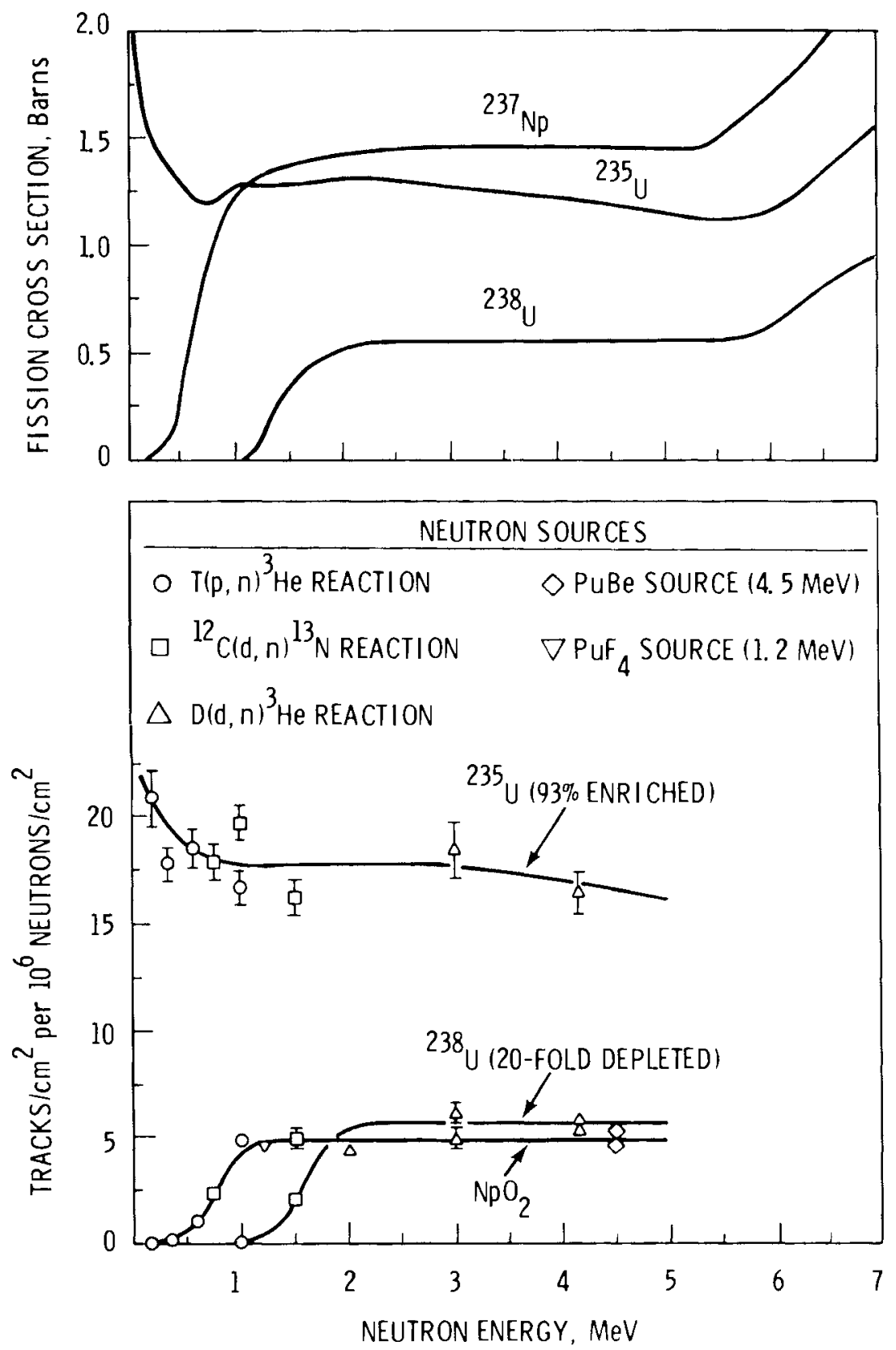

FIGURE B.5. Energy Response of Fission Fragment Track Dosimeter Compared with Fission Cross Sections

(Baumgartner and Brackenbush 1966) 
Nuclear reactions that produce alpha particles have also been used for neutron dosimetry. Usually cellulose nitrate is used to detect the neutrons from ${ }^{6} L i(n, \alpha)^{3} H$ reactions.

Track etch detectors, which detect fission fragments or alpha particles induced in adjacent foils, offer several advantages:

1. accuracy - Fast neutron dose equivalents of 1 rem from unmoderated sources can be measured to within about 15\% using multiple foil detectors; single ${ }^{237} \mathrm{~Np}$ foils offer somewhat reduced accuracy.

2. interference - Fission fragment detectors are insensitive to gamma rays and beta particles to doses below 10,000 rads in polycarbonate plastic.

3. stability - Fission fragment detectors using polycarbonate plastic exhibit virtually no fading at temperatures below $50^{\circ} \mathrm{C}$.

4. environmental factors - Fission fragment detectors are unaffected by humidity, mechanical shock, or temperatures below $50^{\circ} \mathrm{C}$.

5. energy response - A crude spectrometer can be made using multiple foils to correct for the energy response of the detector. The fission cross sections for common foil materials, as compared with the neutron dose equivalent in tissue, are shown in Figure B.6.

The nuclear track detectors employing fissionable foils also have some distinct disadvantages:

1. The fission foils emit gamma rays to which the wearer is exposed. Efforts to keep doses as low as reasonably achievable (ALARA) may preclude their widespread use. Recent advances in preparing thin foils have reduced the exposure at $5 \mathrm{~cm}$ to about $35 \mathrm{mrem} / \mathrm{yr}$ from $0.6 \mathrm{mg}$ of ${ }^{237} \mathrm{~Np}$ and $5 \mathrm{mrem} / \mathrm{yr}$ from $50 \mathrm{mg}{ }^{232} \mathrm{Th}$ (Cross and Ing 1975).

2. There may be administrative prohibitions against the movement and possession of special nuclear materials, especially small amounts of Pu or ${ }^{235} \mathrm{U}$.

3. The dynamic range of the devices may be limited because of track overlap at high neutron doses and artifact backgrounds at low neutron doses. 


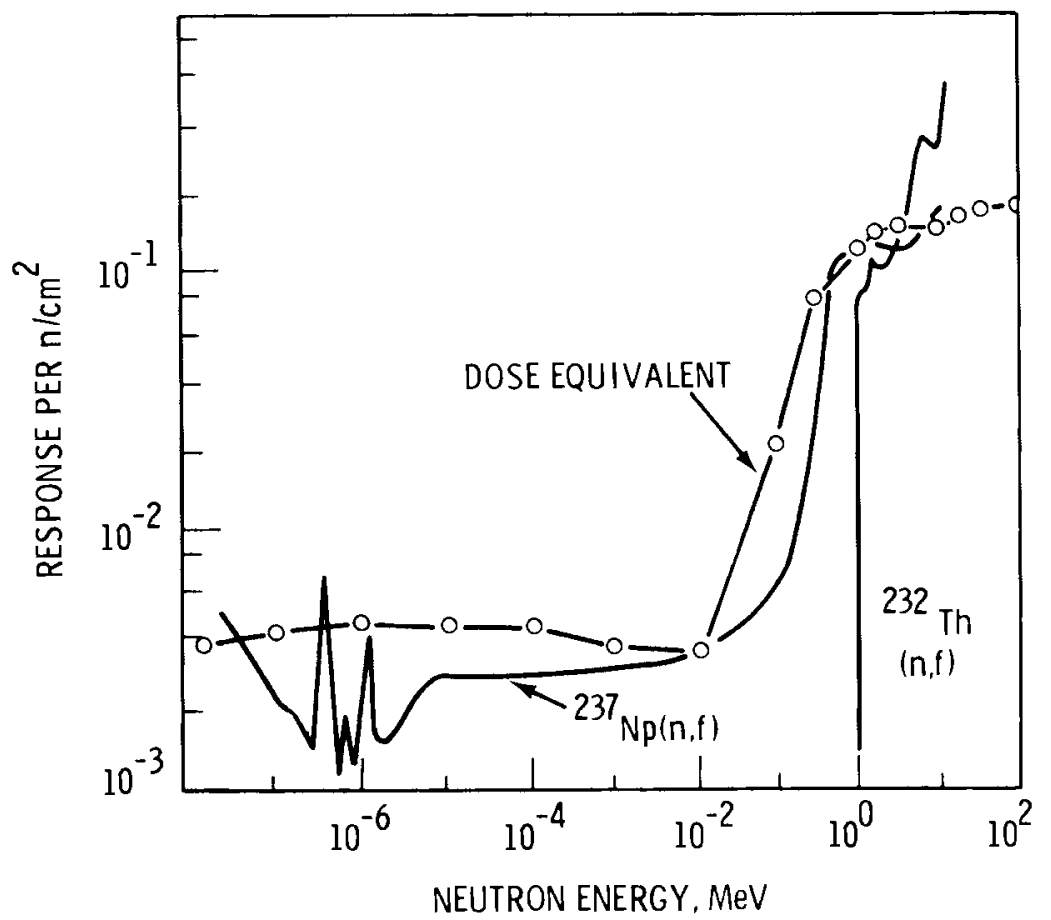

FIGURE B.6. Fission Cross Sections for $232 \mathrm{Th}$ and $237_{\mathrm{Np}}$ Compared with the ICRP Dose Equivalent Per Unit Fluence

\section{Recoil Track Etch Dosimeters}

Neutrons may interact directly in plastic to produce carbon or proton recoils. However, because of the lower LET hydrogen recoils, the tracks are more difficult to observe. Sohrabi (1974) recently demonstrated that recoil tracks could be registered by the electrochemical etching technique introduced by Tommasino (1970). High electric fields at high frequencies cause electrical breakdown at the tips of the tracks, and very vigorous etching occurs (Tommasino and Armellini 1974). The relatively large tracks formed are visible with a microfiche reader or microscope. The technique is sufficiently accurate that one laboratory and a commercial dosimetry service are using this technique with polycarbonate plastic for neutron dosimetry (Griffith, Fisher and Harder 1977; 0swald and wheeler 1977). Unfortunately, the electrochemical etch technique used on polycarbonate plastic has an energy threshold of about $1.5 \mathrm{MeV}$. Other 
materials are being tested in a search for lower energy thresholds (Gammage and Cotter 1977). The monomer allyl diglycol carbonate (trade name CR-39®) has an energy threshold below $200 \mathrm{keV}$ and is being used by a commercial dosimeter laboratory. The dosimeter that uses this material produces tracks from proton recoils. The energy responses of electrochemically etched polycarbonate and CR-39 are shown in Figure B.7. The CR-39 dosimeter appears to be quite useful for fast neutron dosimetry.

Neutron recoil track detectors have all of the advantages listed for fission fragment track detectors with none of the attendant problems of fission foils. They do have some other disadvantages, however:

1. They exhibit a background that corresponds to 20 to $60 \mathrm{mrem}$, depending upon the calibration used (Griffith et al. 1979).

2. They exhibit energy thresholds of about $200 \mathrm{keV}$ for CR-39 and $1.5 \mathrm{MeV}$ for polycarbonate plastic.

Track Counting Techniques

Determining neutron dose equivalent from track etch dosimeters originally involved counting the number of tracks per unit area with a microscope. This method is tedious and causes eye strain, so various other methods were tried: electric conductivity through thin films with holes from track etching, opaque or dyed films that passed light through the track etch holes, etc. None of these methods was really successful in automating the track reading process. A Quantamet system has been developed that scans for tracks of a given range of sizes using a computer, but this system is quite expensive. The best method for automatic reading of the etched fission-fragment holes in plastic films is the spark-replica or spark counting technique (Cross and Tommasino 1970). Thin films are used to detect fission fragment tracks. The tracks are etched out to produce holes in the plastic. The plastic film is placed next to a sheet of aluminized mylar and a metal plate or needle is placed on the opposite side of the plastic. A high voltage is applied and sparks arc through

(B) Registered trademark of Pittsburgh Plate Glass. 


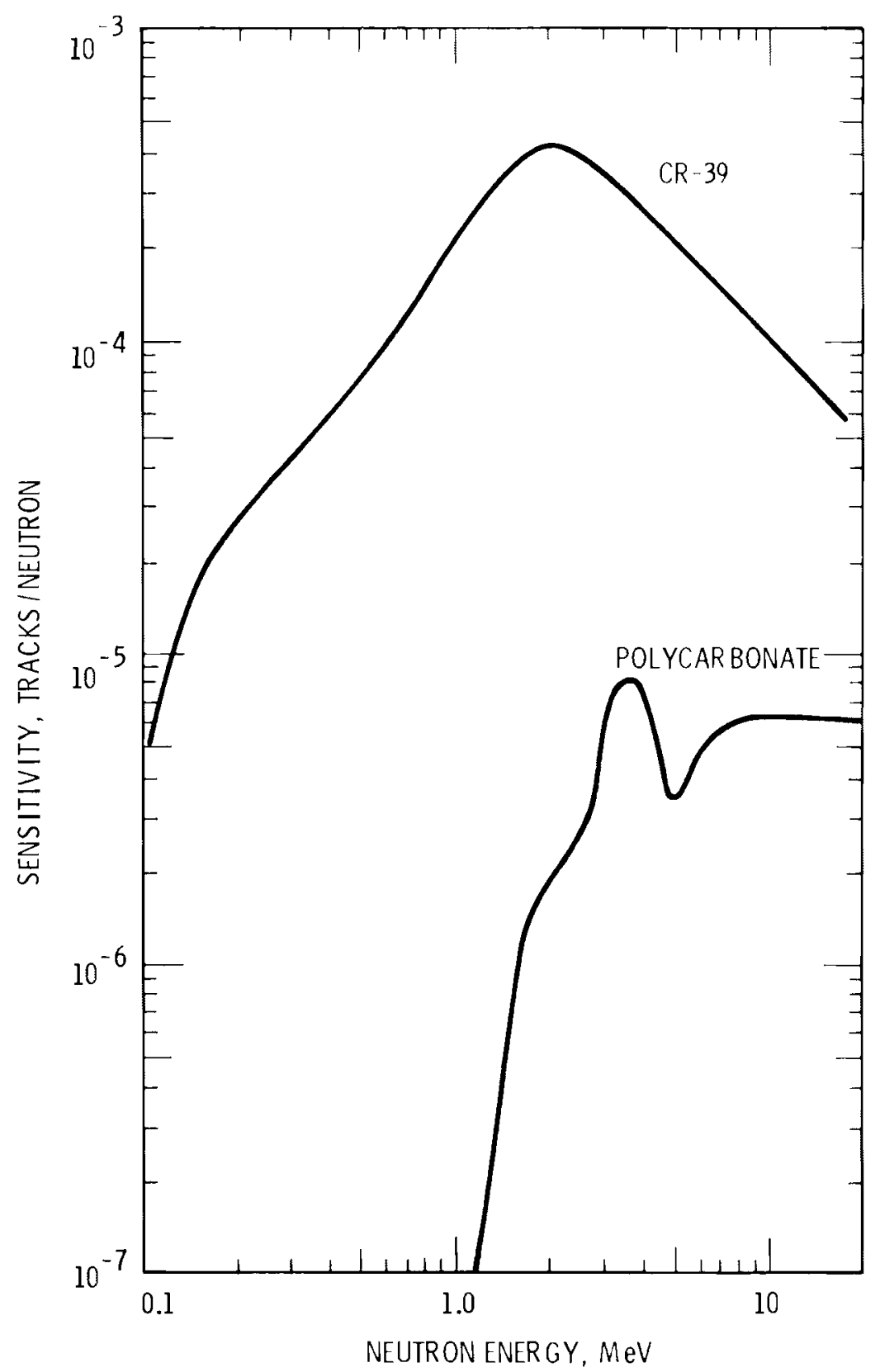

FIGURE B.7. Measured Neutron Energy Response of ElectroChemically Etched Polycarbonate and CR-39 Plastic (Griffith 1980) 
the holes; the number of tracks is determined by counting the number of sparks with a scaler. Multiple sparks through the same hole are prevented by vaporizing away the aluminum film around the hole with the first spark.

A similar principle can be used to construct an alarming dosimeter, using a thin-film capacitor with a fission foil as one of the electrodes. For insulators on ly $10^{-6}$ to $10^{-5} \mathrm{~cm}$ thick, low voltages can be used to power the device, which could be made into a small dosimeter carried in the pocket (Tommasino, Klein and Solomon 1977; Griffith et al. 1979).

The electrochemical etching technique discussed previously is the second major advance in track counting techniques. Using this technique, it is possible to make neutron recoil tracks visible. Details of all of these track etch techniques are discussed in the excellent review article by Griffith et al. (1979).

\section{LYOLUMINESCENT CHEMICALS}

Lyoluminescence, the emission of light when irradiated materials are dissolved, has been investigated by Ettinger and coworkers at the University of Aberdeen. The most sensitive lyoluminescent materials are organic compounds: saccharides (Takavar et a1. 1977), amino acids, proteins, and nucleic acids (Ettinger et a1. 1977a and 1977b). Puite (1977) has used the saccharide mannose to measure as little as 5 rads of mixed radiation. He points out that the dose response is close to that of tissue and that the sensitivity of light emission, i.e., the light emitted for the energy absorbed, is much higher for lyoluminescence than for thermoluminescence. Mannose dissolved in water exhibits a fast-fast effect somewhat similar to some TLDs. Ettinger et al. (1977c) have reported the use of sensitizers such as luminol or lucigenin to increase light output by chemiluminescent oxidation. The sensitivity of this method is limited by impurities in the materials that induce chemiluminescence. Impurities in the reagents used limit the lowest dose that can be measured. At present, it appears that the sensitivity of lyoluminescence must be improved by two orders of magnitude before lyoluminescent materials can be used for personnel neutron dosimetry. This magnitude of improvement is not likely to occur soon. 
DIODES

Silicon PIN (p-type intrinsic n-type) diodes may be useful as dosimeters for fast neutrons. The forward resistance of the diode increases linearly with fast neutron dose over two orders of magnitude, but the device is usable for three or four orders of magnitude before saturation occurs. It is believed that radiation-induced damage in the crystalline lattice causes the increase in forward resistance. The resistance is measured by passing a constant current, usually about $25 \mathrm{~mA}$, through a diode placed in a constant-temperature bath (e.g., an ice bath) to obtain consistent results. Recently, pulsed current techniques have been used so that the diode does not heat up and change resistance during the measurement. Attempts have been made to improve the performance of diodes (Lucas 1977). Diodes with a 20-mV/rad voltage drop across the diode at 25-mA constant current were produced. The minimum sensitivity was about $500 \mathrm{mrem}$, which could be useful for a yearly dosimeter exchange.

Silicon diodes have several advantages:

1. They are insensitive to garma rays and beta particles.

2. They are stable over long periods and can be used as integrating dosimeters.

3. They are unaffected by environmental factors.

4. They are small and easily worn in security badges.

5. The readout of the devices is simple if a constant temperature is maintained, or if diodes with low-temperature coefficients are used.

The disadvantages of diodes include the following:

1. They are not sensitive enough for use as routine dosimeters. The lower detection limit of 500 mrem needs to be improved by an order of magnitude.

2. Low precision and consistency of response between different diodes is a problem. A calibration factor for each individual diode may be necessary. 
3. For a high initial cost, the units can be reissued to the same person and used as an integrating dosimeter.

4. The diodes do not respond to all neutron energies. They have a relatively constant response to fast neutrons in the energy range of 200 or $300 \mathrm{keV}$ to $16 \mathrm{MeV}$ or higher.

Diodes show promise for use as a fast neutron dosimeter if the lower limit of detection can be improved. The relatively flat energy response and dose integrating capability are distinct advantages over existing dosimeters.

DEVICES USING ELECTRICAL CONDUCTIVITY IN PLASTICS

Fadel (1977) has reported a method of measuring fast neutron doses of 0.001 rad to 7 rads from an AmBe source by measuring changes in the resistivity of a cellulose acetate film covered by a cellulose acetate proton recoil irradiator. Simple resistivity measurements were made at room temperature, and as little as $1 \mathrm{mrad}$ could be detected. The film gave a record of the accumulated neutron dose free of interference from gamma rays. Fadel states that the method is reproducible and accurate if the temperature is kept constant. This method should be investigated further.

THERMALLY ST IMULATED EXOELECTRON EMISSION (TSEE) DEVICES

About a decade ago, there was great interest in dosimetry using the electron emitted when an irradiated material was heated. This method was reported to be quite sensitive for detecting gamma rays, and it was proposed that it could also be used for neutron dosimetry (Becker and Crase 1970). In the United States, interest in this dosimetry technique almost ceased when measurements (Gammage et al. 1974) indicated that the neutron response in beryllium oxide was only about $11 \%$ of the photon response, and that the device would not be useful in mixed radiation fields. The TSEE technique was not abandoned in Europe, and research has continued there. Lausch and Huebner (1974) and Jaek, Savikhin and Kaambre (1974) reported TSEE detectors made from calcium sulfate and carbon. However, it still appears that the TSEE technique offers little hope of being useful as a personnel neutron dosimeter in mixed radiation fields. 


\section{ELECTRETS}

A novel device for use as an alarming gamma dosimeter, using electrets, was presented by French scientists at the IAEA Symposium on Advances in Radiation Protection Monitoring in Stockholm, Sweden, in June 1978 (Perino, Lewiner and Dreyfus 1978). Electrets are the electric analog of a permanent magnet. The device consists of two electrets placed close to one another and held together by mutual electric attraction. One of the electrets is on a spring. When the device is exposed to gamma rays, the electric attraction is diminished, and the spring separates the electrets and sets off an alarm. The amount of radiation the electret is exposed to can be determined by applying an external electric field.

At the time the paper was presented, the device had been tested only with gamma rays, but it was expected to function with neutrons also. Since the electret material has a composition similar to that of tissue, this device may be a good fast neutron dosimeter that can be read out easily. It should be investigated further.

\section{ELECTRONIC DEVICES}

Recent advances in electronics may make it possible to build new types of neutron dosimeters at a reasonble cost. Colvett (1978) has pointed out that it is possible to separate neutron events from gamma events in a counter without using gas multiplication. He proposes building a personnel neutron dosimeter capable of alarming at any neutron dose by using a small hydrogen-neutron counter with a little ${ }^{3}$ He in it to provide thermal neutron sensitivity. No high voltages would be involved, and recently developed microelectronic circuits could be used to discriminate neutron- and photon-induced events and to store them in scalers. Several European scientists have built a somewhat similar device using a cadmium-covered ${ }^{3}$ He counter and a polyethylene moderator to produce an energy-independent albedo dosimeter for neutrons (Heinzelmann, Opladen and Schueren 1977; Gibson 1977). They state that, by an adjustment of the discriminator threshold, the device can be made energy independent from $0.5 \mathrm{eV}$ to $14 \mathrm{MeV}$, with the energy responses matching tissue 
response to within a factor of two. Lucas (1978) has also described a ${ }^{3} \mathrm{He}$ counter with a discriminator whose response to fast neutrons nearly matches that of a tissue-equivalent chamber.

These methods seem to hold great promise for the development of a fast neutron dosimeter in which the neutron dose equivalent can be differentiated from the photon dose equivalent. The dosimeter could be set to alarm at any level, and appears to have good sensitivity. It is technically feasible to build such a device today, but the costs are prohibitive. With further advances in large-scale integrated circuits, it may be practical to build electronic dosimeters using new memory storage devices.

Another approach would be to build a tissue-equivalent proportional counter (TEPC) into a small, portable dosimeter. This device would have many advantages. Its energy response would very closely match that of tissue. It could be made quite sensitive by using parallel plates, since the sensitivity is proportional to the surface area of the tissue-equivalent plastic. Under certain conditions, the TEPC is self-calibrating; it is an absolute dosimeter that does not require further calibration, unlike almost every other type of neutron dosimeter. With advances in microelectronics, it may be possible to build a simple multichannel analyzer to record pulse height or energy loss data from the TEPC. From the event size spectra from a TEPC, it is possible to derive dose distributions as a function of LET and hence to determine effective quality factors and dose equivalents. The algorithms for quality factor and dose-equivalent determinations already exist for spherical counters. Because the TEPC measures absorbed dose as a function of lineal energy, quality factors could be determined directly if they were redefined in terms of lineal energy (Rossi 1977b).

In addition to the many advantages of using TEPCS, there are also distinct disadvantages. It would be extremely expensive to build such a dosimeter today; each unit would cost several thousand dollars. Inexpensive electronics must be developed for such a system to be practical. 


\section{SUPERHEATED DROP DETECTORS}

The superheated drop detector, a miniature bubble chamber invented by Dr. Robert Apfel (1979), is a simple device for the detection of neutrons and charged particles. A liquid like Freon is injected into a viscous gel under pressure, or an emulsion of very small droplets is created in a gel. When the pressure is released, the Freon becomes superheated. A charged particle or neutron recoil can trigger nucleation in the superheated liquid and instantly convert it to a gas. Photons cannot impart enough energy to cause vapor formation, so the device is completely insensitive to gamma and $x$ rays. Apfel (a) has developed a "thermal spike" theory to account for the conditions necessary for nucleation and the changing of the superheated liquid to a gas. If enough energy is imparted in a small volume, a microscopic bubble is formed. If the diameter of the bubble is large enough, the bubble becomes thermodynamically unstable and grows; if not, surface tension collapses the bubble. Apfel has shown that the critical radius of this microscopic gas bubble necessary for nucleation is

$$
R_{C}=2 Y(T) / \Delta P
$$

where

$$
\begin{aligned}
Y(T) & =\text { the surface tension of the superheated liquid } \\
\Delta P & =P_{V}(T)+P_{g}-P_{0} \\
P_{v}= & \text { the pressure of the vapor in the cavity } \\
P_{g}= & \text { the partial pressure associated with the noncondensible, } \\
& \text { dissolved gas } \\
P_{0}= & \text { the externally applied pressure. }
\end{aligned}
$$

The quantity $\Delta P$ is a measure of the degree of superheat of the liquid. As $\Delta P$ increases, the critical radius $R_{c}$ grows smaller and less heat is required for drop vaporization. The heat released along the neutron recoil can be calculated from the stopping power or LET. Heavier ions such as carbon have the highest LET and are the most effective in vapor formation.

(a) Paper to be published in Nuclear Instrumentation and Methods. 
A simple dosimeter can be made by placing inside a small container the superheated liquid drops contained in a viscous gel, with a manometer-like device to record changes in the volume from gas formation. Another alternative would be to mix the superheated liquid with a dye, which would be released and cause an immiscible liquid to change colors when the superheated liquid was vaporized by neutron irradiation. Both of these devices would be self-reading.

There are many advantages to the superheated drop detector:

1. It is inexpensive; the materials required cost on ly a few cents.

2. It is totally insensitive to gamma rays.

3. Any desired sensitivity can be achieved by changing the amount of superheated liquid.

4. The dosimeter can be made to be self-reading as described above.

5. The dosimeter can be made to be sensitive to thermal neutrons by adding boron or lithium compounds.

6. A crude neutron energy spectrometer can be constructed by using mixtures of liquids with various degrees of superheat and hence various energy thresholds.

There are also several disadvantages:

1. The energy response is not yet known.

2. The dosimeter appears to be sensitive to temperature. Its energy threshold depends on the degree of superheat. This dependence may not be a problem if a liquid with a very low boiling point is used.

3. Mechanical shock may trigger vaporization.

Virtually nothing is known about the energy sensitivity and thresholds of superheated drop detectors. A great deal of work needs to be done before they can be used as neutron dosimeters. 


\section{REFERENCES}

Anderson, M. E., and S. L. Crain. 1977. "A Combination TL-Film Personnel Neutron Dosimeter." In Sixth ERDA Workshop on Personnel Neutron Dosimetry. PNL-2449, Pacific Northwest Laboratory, Richland, Washington.

Apfel, R. E. 1979. Detector and Dosimeter for Neutrons and Other Radiations. U.S. Patent 4,143,274, U.S. Patent Office, Washington, D.C.

Bartlett, W. T. 1978. "Personnel Neutron Monitoring at NRPB." In Seventh DOE Workshop on Personnel Neutron Dosimetry. PNL-2807, Pac if ic Northwest Laboratory, Richland, Washington.

Barton, T. P., and C. E. Easterly. 1979. Neutron Personnel Dosimetry Considerations for Fusion Reactors. ORNL/TM-6756, Oak Ridge National Laboratory, Oak Ridge, Tennessee.

Baumgartner, W. V., and L. W. Brackenbush. 1966. "Neutron Dosimetry Using the Fission Fragment Damage Principle." BNWL-SA-516, Pac ific Northwest Laboratory, Richland, Washington.

Becker, K. 1973. Long-Term Stability of Film, TLD, and Other Integrating Dosimeters in Warm and Humid Climates. ORNL/TM-4297, Oak Ridge National Laboratory, Oak Ridge, Tennessee.

Becker, K., and K.W. Crase. 1970. "A Sensitive Integrating Fast Neutron Dosimeter Based on TSEE." Nucl. Instrum. Methods 82:297.

Becker, K., F. F. Haywood, P. T. Perdue and J. H. Thorngate. 1975. Fast-Neutron Solid-State Dosimeter. U.S. Patent 3,896,306, U.S. Patent Office, Washington, D.C.

Becker, K., T. D. Tham and F. F. Haywood. 1973. "Compounds of TLDs and High-Melting Organics for Fast Neutron Personnel Dosimetry." In Volume 1 of Proceedings of the Third International Congress of the International Radiation Protection Association. CONF-730907, National Technical Information Service, Springfield, Virginia.

Blackstock, A. W., J. R. Cortez, G. J. Littlejohn and E. Storm. 1978. Neutron Response of a New Albedo-Neutron Dosimeter. LA-UR-78-40, Los Alamos Scientific Laboratory, Los Alamos, New Mexico.

Burger, G., F. Griinauer and H. Paretzke. 1971. "The Applicability of Track Detectors in Neutron Dosimetry." In Advances in Physical and Biological Radiation Detectors: Proceedings of a Symposium, pp. 349-358. International Atomic Energy Agency, Vienna, Austria. 
Colvett, R. D. 1978. "Yet Another Approach to Neutron Personnel Dosimetry." Health Phys. $34: 277$.

Cross, W. G., and H. Ing. 1975. "The Use of $237 \mathrm{~Np}$ in Personnel Dosimeters for Fast Neutrons." Health Phys. 28:511.

Cross, W. G., and L. Tommasino. 1970. "A Rapid Reading Technique for Nuclear Particle Damage Tracks in Thin Foils." Radiat. Eff. 8:85.

Distenfeld, C. H. 1973. "Summary of Personnel Neutron Dosimetry Development at Brookhaven National Laboratory." In Fourth AEC Workshop on Personnel Neutron Dosimetry. BNWL-1717, Pac if ic Northwest Laboratory, Richland, Washington.

Endres, G. W. R. 1971. "The Hanford Thermoluminescent Multipurpose Dosimeter." In Second AEC Workshop on Personnel Neutron Dosimetry, ed. C. M. Unruh. BNWL-1616, Pac if ic Northwest Laboratory, Richland, Washington.

Endres, G. W. R. 1975. "Fast Neutron Dosimetry Using High Temperature Peaks in LiF and $\mathrm{CaF}_{2}$ :TM." In Fifth ERDA Workshop on Personnel Neutron Dosimetry. BNWL-1934, Pac ific Northwest Laboratory, Richland, Washington.

Ettinger, K. V., J. R. Mallard, S. Spirath and A. Takavar. 1977a.

"Lyoluminescence Dosimetry with Some Saccharides." Phys. Med. Biol. $22: 481$.

Ettinger, K. V., R. W. Rowe, J. R. Mallard, A. Takavar, J. P. Sephton and D. I. Thwaites. 1977b. "The Lyoluminescence of Amino Acids, Proteins, Nucleic Acids and Its Applications." In Proceedings of the Fifth International Conference on Luminescence Dosimetry, Sao Paulo, Brazil, ed. A. Scharmann. Physikalisches Institut, Justus-Liebig Universitat, Giessen, Federal Republic of Germany.

Ettinger, K. V., A. Takavar, J. R. Mallard and G. Buchau. 1977c. "Lyoluminescence Dosimetry with Sensitizers." In Recueil des Communications: Proceedings, Paris, 24-30 April 1977. Fourth International Congress, International Radiation Protection Association, Paris.

European Organization for Nuclear Research. 1976. Ninth International Conference on Solid State Nuclear Track Detectors, Neuherberg/Munchen. CONF-760964-18, National Technical Information Service, Springfield, Virginia.

Fade1, M. A. 1977. "A Devised Electric Conductivity Method for Measuring Personnel Neutron Doses." Radiat. Eff. 31:229. 
Fleischer, R. L., P. B. Price and R. M. Walker. 1965. "Neutron Flux Measurement by Fission Tracks in Solids." Nucl. Sci. Eng. 22:153-156.

Gammage, R. B., and S. J. Cotter. 1977. "Evaluation of Different Polymers for Fast Neutron Personnel Dosimetry Using Electrochemical Etching." In Sixth ERDA Workshop on Personnel Neutron Dosimetry. PNL-2449, Pacific Northwest Laboratory, Richland, Washington.

Gammage, R. B., F. F. Haywood, N. H. Lee and J. S. Cheka. 1974. Fast Neutron Monitoring with Exoelectron Emitting Be0 Dosimeters. ORNL/TM-4624, Oak Ridge National Laboratory, Oak Ridge, Tennessee.

Gibson, J. A. B. 1977. "Neutron Dosimetry System for Use in Processing Plants." In Recueil des Communications: Proceedings, Paris, 24-30 April 1977. Fourth International Congress, International Radiation Protection $\overline{\text { Association, Paris. }}$

Gibson, J. A. B. 1978. "The Harwe 11 Neutron Dosimetry System." In Seventh DOE Workshop on Personnel Neutron Dosimetry. PNL-2807, Pacific Northwest Laboratory, Richland, Washington.

Gomma, M. A., and G. Hossi1. 1971. "Neutron Dose Estimation Using a Natural Uranium Fission Fragment Track Personnel Dosimeter." In Advances in Physical and Biological Radiation Detectors: Proceedings of a Symposium. Internationa 1 Atomic Energy Agency, Vienna, Austria.

Griffith, R. V. 1974. Particle Registration in Dielectric Materials: A Bibliography. UCRL-51568, Lawrence Livermore Laboratory, University of California, Livermore, California.

Griffith, R. V., J. C. Fisher and C. A. Harder. 1977. Development of a Combined Etch Track-Albedo Dosimeter. UCRL-50007-77-1, Lawrence Livermore Laboratory, University of California, Livermore, California.

Griffith, R. V., D. E. Hankins, R. B. Gammage, L. Tommasino and R. V. Wheeler. 1979. "Recent Developments in Personnel Neutron Dosimeters - A Review." Health Phys. 36:235-260.

Griffith, R. V. 1980. Hazards Control Progress Report No. 58, April Through September 1979. UCRL-50007-79-2, Lawrence Livermore Laboratory, University of California, Livermore, California.

Hankins, D. E. 1972. Factors Affecting the Design of Albedo Neutron Dosimeters Containing Lithium Fluoride Thermoluminescent Dosimeters. LA-4832, Los Alamos Scientific Laboratory, Los ATamos, New Mexico.

Hankins, D. E. 1973. A Sma11, Inexpensive Albedo-Neutron Dosimeter. LA-5261, Los Alamos Scientific Laboratory, Los Alamos, New Mexico. 
Hankins, D. E. 1975. "The Effect of Energy Dependence on the Evaluations of Albedo Neutron Dosimeters." In Proceedings of the Ninth Midyear Topical Symposium. Health Physics Society, Denver, Colorado.

Harrison, K. G. 1978. "The AERE Neptunium Dosimeter." In Seventh DOE Workshop on Personnel Neutron Dosimetry. PNL-2807, Pacific Northwest Laboratory, Richland, Washington.

Heinzelmann, M., G. Opladen and H. Schueren. 1977. "Energy Independent Albedo-Dosimeter for Neutrons." In Recueil des Communications: Proceedings, Paris, 24-30 April 1977. Fourth International Congress, International Radiation Protection Association, Paris.

Hoy, J. E. 1972. Personnel Albedo Neutron Dosimeter with Thermoluminescent $6 \mathrm{Li}$ and $7_{\mathrm{LiF}}$. DP-1277, E. I. du Pont de Nemours and Company, Inc., Savannah River Plant, Aiken, South Carolina.

Jaek, I., F. Savikhin and H. Kaambre. 1974. "LET Dependence of TSL and TSEE Yield as a Basis for a Fast Neutron Dosimetry Method." In Volume 1 of Proceedings of the Fourth International Conference on Luminescence Dosimetry, ed. T. Niewiadomski. Institute of Nuclear Physics, Krakow, Poland.

Kapsar, B. M., and A. C. Lucas. 1977. "Neutron and Gamma Ray Detection Using Thermoluminescence of $\mathrm{CaF}_{2}: \mathrm{Tm}$." In Abstracts of the Twenty-Second Annual Meeting of the Health Physics Society, Atlanta, Georgia, paper P/14. Health Physics Society, Denver, Colorado.

Knight, A. 1974. "Fading of Proton Recoil Tracks in Nuclear Emulsions." Health Phys. 27:606.

Kocher, L. F., G. W. R. Endres, L. L. Nichols, D. B. Shipler and A. J. Haverfield. 1971. "The Hanford Thermoluminescent Multipurpose Dosimeter." BNWL-SA-3955, Pac if ic Northwest Laboratory, Richland, Washington.

Korba, A., and J. E. Hoy. 1969. "A Thermoluminescent Personnel Neutron Dosimeter." Health Phys. 18:581.

Lausch, W., and K. Huebner. 1974. "CaSO4 $-\mathrm{Fe}$ as a New TSEE Dosimeter." In Volume 2 of Proceedings of the Fourth International Conference on Luminescence Dosimetry, ed. T. Niewiadomski. Institute of Nuclear Physics, Krakow, Poland.

Lucas, A. C. 1977. "The Design of a Silicon PIN Diode for Fast Neutron Dosimetry." In Abstracts of the Twenty-Second Annual Meeting of the Health Physics Society, Atlanta, Georgia, paper P/13. Health Physics Society, Denver, Colorado.

Lucas, A. C. 1979. "The Use of Helium-3 Filled Proportional Counter as a Sensitive Dose or Dose Equivalent Meter." IEEE Trans. Nucl. Sci. NS26: 770 . 
Lucas, A. C., and B. M. Kapsar. 1977. "The Thermoluminescence of Thulium Doped Calcium Fluoride." In Proceedings of the Fifth International Conference on Luminescence Dosimetry, Sao Paulo, Brazil, ed. A. Scharmann. Physikalisches Institut, Justus-Liebig Universitat, Giessen, Federal Repubiic of Germany.

Oswa ld, R. A., and R. V. Wheeler. 1977. "Energy Dependence of ElectroChemically Processed Track Etch Dosimeters." In Abstracts of the Twenty-Second Annual Meeting of the Health Physics Society, Atlanta, Georgia. Health Physics Society, Denver, Colorado.

Perino, D., J. Lewiner and G. Dreyfus. 1978. "Dispositif Nouveau de Detection de Rayonnements Ionizants." In Advances in Radiation Protection Monitoring: Proceedings of a Symposium. IAEA-SM-229/136, International Atomic Energy Agency, Vienna, Austria.

Petre, S. 1973. "Personnel Neutron Dosimeter, Based on Automatic FissionTrack and Spark Counting for Routine and Emergency Use." In Volume 2 of Neutron Monitoring for Radiation Protection Purposes: Proceedings of a Symposium. International Atomic Energy Agency, Vienna, Austria.

Piesch, E., and B. Burgkhardt. 1978a. "Advances in Albedo Neutron Dosimetry." In Advances in Radiation Protection Monitoring: Proceedings of a Symposium. IAEA-SM-229/5, International Atomic Energy Agency, Vienna, Austria.

Piesch, E., and B. Burgkhardt. 1978b. "The Role of an Analyzer Type Albedo Dosimeter in Routine Monitoring and the Current Situation for the Calibration Technique." In Seventh DOE Workshop on Personnel Neutron Dosimetry. PNL-2807, Pacific Northwest Laboratory, Richland, Washington.

Price, P. B., and R. M. Walker. 1963. The Use of Mica as a Convenient and Simple Dosimeter of Both Slow and Fast Neutrons. 63-RL-(3253M), General ETectric Research Laboratory, Schenectady, New York.

Puite, K. J. 1977. "Perspectives for Using Lyoluminescence in Photon and Fast Neutron Fields." In Recueil des Communications: Proceedings, Paris, 24-30 April 1977. Fourth International Congress, International Radiation Protection Association, Paris.

Rzyski, R., S. Watanabe and C. M. Suntga. 1977. "Fast Neutron Dosimetry Using Fluorite Mixed with Hydrogenous Materials." In Proceedings of the Fifth International Conference on Luminescence Dosimetry, Sao Paulo, Brazil, ed. A. Scharmann. Physikalisches Institut, Justus-Liebig Universitat, Giessen, Federal Republic of Germany. 
Sayed, A. M., and E. Piesch. 1974. Study of the Latent Fading of the NTA Film and Track Etching Detectors at Various Temperatures and Humidities. KFK-2032, Kernforschungszentrum, Kar 1sruh, Federal Republic of Germany.

Sohrabi, M. 1974. "The Amplification of Recoil Particle Tracks in Polymers and Its Application in Fast Neutron Personnel Dosimetry." Health Phys. $27: 598$.

Takavar, A., J. V. Ettinger, J. R. Mallard, N. Atari and S. Srirath. 1977. "Progress in Lyoluminescence Dosimetry Using Saccharides." In Proceedings of the Fifth International Conference on Luminescence Dosimetry, Sao Paulo, Brazil, ed. A. Scharmann. Physikalisches Institut, Justus-Liebig Universitat, Giessen, Federal Republic of Germany.

Tommasino, L. 1970. Electrochemical Etching of Damaged Track Detectors by HV Pulse and Sinusoided Waveforms. RT/PROT(7I) 1970, Comitato Nazionale Energia Nucleare, Rome, Italy.

Tommasino, L., and C. Armellini. 1974. "Production of Treeing in Insulators and Damage Tracks." J.Appl. Phys. 45:949.

Tommasino, L., N. Klein and P. Solomon. 1977. "Fission Fragment Detection by Thin Film Capacitors--I. Breakdown Counter." Nucl. Track Detect. 1:63.

U.S. Nuclear Regulatory Commission. 1977. Rule Making Exemption from Licensing Requirements for Personnel Neutron Dosimeters that Contain Natura1 Thorium. NUREG-0137, Washington, D.C.

Walker, R. M., P. B. Price, and R. L. Fleischer. 1963. "A Versatile, Disposable Dosimeter for Slow and Fast Neutrons." Appl. Phys. Lett. $3: 28-29$.

Yule, T. V. 1973. "The Solid State Track-Recorder Fast-Neutron Dosimeter Employed at Argonne National Laboratory." In Fourth AEC Workshop on Personnel Neutron Dosimetry. BNWL-1717, Pac if ic Northwest Laboratory, Richland, Washington. 
APPENDIX C

PERSONNEL NEUTRON DOSIMETER SURVEY FORM AND RESPONSES 
APPENDIX C

PERSONNEL NEUTRON DOSIMETER SURVEY FORM

AND RESPONSES

$\operatorname{NAME}(S)$

TELEPHONE : FTS

COMMERCIAL

ADDRESS:

Would you like a copy of the final report? Yes

No

\section{TYPES OF NEUTRON DOSIMETERS}

What type of neutron dosimeters are used? If the dosimeter is described in a document, please give a reference. If a commercial dosimeter service is used, please indicate which one.

TLD a lbedo:

NTA emulsion:

Track etch:

Fission foil

Other ( $p$ lease describe):

Neutron/gamma ratios:

Extremity dosimeters:
13 sites

6 sites (Landauer - 1 site) Experimental use at 1 site

2 sites -- Cd \& film albedo; combination NTA \& TLD albedo

1 site -- used for extremity dose equivalent

1 site 
Is the dosimeter system automated?
Fully automated dosimeter reader:
2 sites
Semi-automated -- dosimeter material
manually placed in "reader":
3 sites
Manual system -- dosimeter read out
by hand:
3 sites
Neutron dosimeter results in computer file:
7 sites

\section{DOSIMETER RESPONSE}

Has the energy response been measured by the following neutron energies? Please give any documentation of energy response.

Slow neutrons (thermal to $1 \mathrm{eV}$ ): $\quad 8$ sites

Intermediate-energy neutrons

(1 ev to $100 \mathrm{keV})$ : 1 site

Fast neutrons (above $100 \mathrm{keV}$ ): 13 sites

Has the angular response been measured?
No:
5 sites
Yes - reference:
3 sites

What is the sensitivity of the dosimeter to neutrons of various energies (for example, 20 mrem $+50 \%$ for fast neutrons and 1 mrem $\pm 50 \%$ for thermal neutrons)?

Dosimeter sensitive to:

Slow (thermal to $1 \mathrm{eV}$ ):

Intermediate ( $1 \mathrm{eV}$ to $100 \mathrm{keV})$ :

Fast (above $100 \mathrm{keV}$ ):
Minimum detectable dose \pm confidence leve 1

Range $0.01 \mathrm{mrem} \pm 50 \%$ to $50 \mathrm{mrem}+50 \%$; average $1 \mathrm{mrem}$

Range $10 \mathrm{mrem} \pm 40 \%$ to $35 \mathrm{mrem} \pm 40 \%$; average 20 mrem

Range 1 mrem \pm ? to 50 mrem $\pm 50 \%$; average $30 \mathrm{mr} \overline{\mathrm{em}}$ 
Does the dosimeter respond to environmental factors such as:

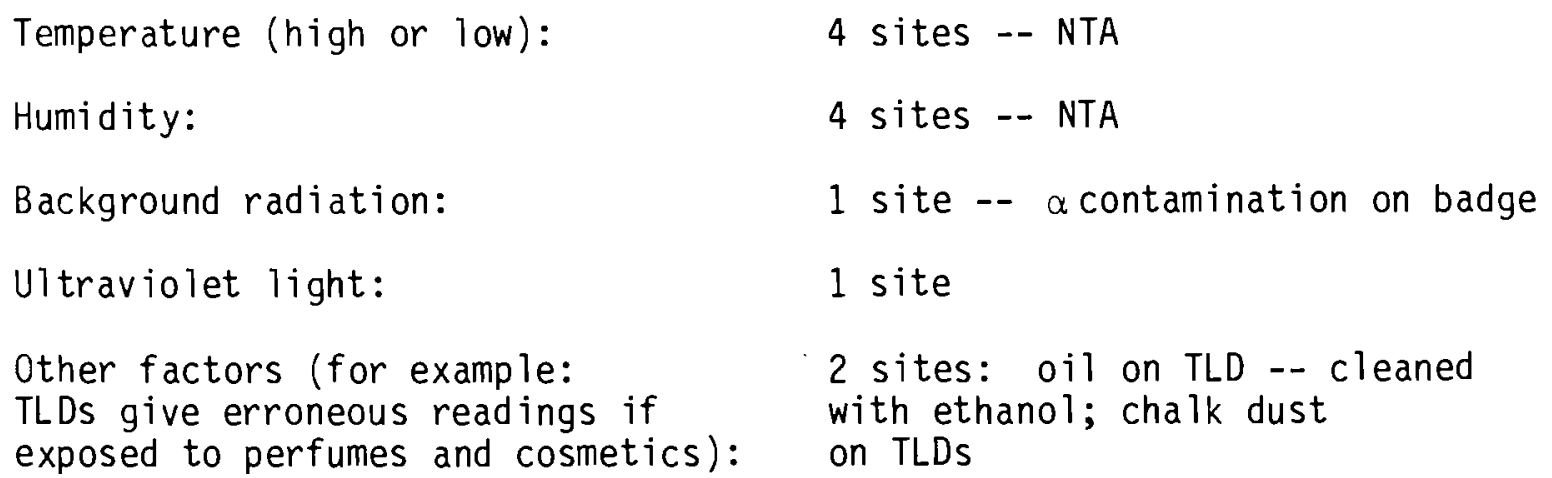

What is the effect of mixed radiation fields on the neutron dose determination?

Independent of $\gamma$ rays

Interference from high doses of $\quad 8$ sites -- $Y / n$ of $4,7,20$, gamma rays or beta particles above 100 (TLD); NTA above 1 rem $\mathrm{Y} / \mathrm{n}$ ratio of

Other interfering particles (hadrons)

Is the dosimeter dose-rate-dependent?

No:

4 sites

Yes, above a dose rate

level of $\mathrm{rad} / \mathrm{hr}$

\section{FACILITIES DOSIMETERS ARE USED IN}

In what type of facilities are the neutron dosimeters used?

Reactor:

Accelerator:

D-T generator:

Chemical separations:

Fusion device:
11 sites

11 sites

8 sites

5 sites

3 sites 
Isotopic neutron source: $\quad 10$ sites

Medical sources ( ${ }^{252} \mathrm{Cf}$ implant): 2 sites

Nuclear fuel fabrication: $\quad 7$ sites

Others ( $p$ lease describe): $\quad$ Pu or weapons -- 7 sites

TRU recovery -- 5 sites

well-logging/waste -- 1 site

Please make an estimate of the types and numbers of employees issued neutron dosimeters.

Response: total number issued dosimeters is 27,500. Most not classified as to type. Those classified are listed below.

Health physicists/technicians 298

Reactor operators/technicians 273

Accelerator operators 1938

$\begin{array}{ll}\text { Medical staff } & 20\end{array}$

Nuclear fuel fabrication technicians $\quad 147$

Craftsmen (pipefitters, electricians) 601

Visitors to Facilities $\quad 720$

Plutonium manufacture $\quad 1765$

Chemical separations 265

Others (please specify) $\underline{1229}(\mathrm{a})$

TOTAL classified by group: $\quad 7256$

What is the energy spectrum the neutron dosimeters are exposed to in the field? Slow (thermal to $1 \mathrm{eV}$ ): $\quad 5$ sites

Intermediate ( $1 \mathrm{eV}$ to $100 \mathrm{keV}): \quad 6$ sites

Fast (above $100 \mathrm{keV}$ ): $\quad 9$ sites

(a) Mostly "researchers" -- scientists and engineers at accelerator sites, or casual radiation workers. 
Has the energy spectrum the dosimeters are used in been measured or calculated? If so, describe the neutron spectrometer or measurement technique used.
Multisphere (Bonner Sphere):
5 sites
3He spectrometer:
2 sites
Scintillation spectrometer:
1 site
Proton recoil spectrometer:
3 sites
Monte Carlo computer code
calculations:
3 sites (accelerators)

\section{CALIBRATIONS}

What type of neutron sources are used for dosimeter calibrations (for example, 80-gram PuBe sources)?
PuBe:
9 sites, 1 to $160 \mathrm{~g}$
252 Cf :
5 sites, avg. $10 \mu \mathrm{g}$
$\mathrm{PuF}_{4}$ :
4 sites
AmBe
Other:
$\mathrm{PuF}_{4}+\mathrm{PuO}_{2}$ (PuLi, PuB -- not
None routinely used)

Are corrections applied for changes in neutron source strength with time?
Yes -- time interval:
5 to $10 \mathrm{yr}$ for PuBe;
every time for $\mathrm{Cf}$

No 
Please describe the exposure conditions for calitrations (for example, is the calibration performed in a large room with an aluminum grate for a floor to minimize scatter, or is the exposure made in a $10-\mathrm{ft}$ by $20-\mathrm{ft}$ room with thick concrete walls and floor?)

Low-scatter room:

Medium-scatter:

High-scatter:
1 site -- large room ( $>30 \mathrm{ft} \times 30 \mathrm{ft}$ ), thin walls, open grating for floor

6 sites -- large room, concrete floors and walls, source elevated $>5 \mathrm{ft}$ from floor

3 sites -- small room (10 ft $\times 20 \mathrm{ft}$ ), thick concrete walls and floor

Conditions under which dosimeter is calibrated:

Unidirectional neutron beam

Isotropic neutron source:

7 sites

Free air exposure -- no phantom:

4 sites

Dosimeter exposed on phantom:

4 sites

Material phantom is composed of:

Water:

3 sites

Polyethylene:

2 sites

Tissue-equivalent liquid

Remab phantom:

1 site (available at 2 other sites but not routinely used)

Other:

1 site -- lucite

1 site -- paraffin

Phantom rotated for isotropic irradiation:

2 sites -- rotation used for wrist dosimeter at 1 site; phantom rotated for isotropic exposure at 1 site 
Is a moderated source used (for example, a source in a water tank or graphite pile for thermal neutrons)? Please describe the size and type of moderator material.
Bare source:
6 sites
$\mathrm{D}_{2} \mathrm{O}$-- Thickness
$\mathrm{cm}$ :
2 sites -- center of 55-gal drum for thermals
$\mathrm{H}_{2} \mathrm{O}--$ Thickness $\mathrm{cm}$
Carbon -- Thickness $\mathrm{cm}$ :
1 site -- sigma pile for thermal neutrons
Other:
1 site -- lucite and polyethylene for thermal neutrons

Please describe any source calibrations used (for example, measurements with a tissue-equivalent proportional counter to determine dose or a long counter to determine neutron flux).
Manganese sulfate bath to
determine yield:
2 sites
Long counter to measure flux:
3 sites
Tissue-equivalent proportional counter or ion chamber to
measure neutron dose:
1 site
Other device -- please describe:
3 sites -- $A B$ rem meter; standard graphite pile; long counter

Is the source calibration directly traceable to the U.S. National Bureau of Standards?
Calibrated at NBS:
4 sites
Intercompared against another source:
4 sites
Use manufacturer's values:
1 site

Other 
What is the angular emission of neutrons from the source?

Assumed to be isotropic:

6 sites

Angular measurements made -- please describe or give reference:

2 sites

What is the dose-equivalent rate as a function of distance from the source?

Inverse square behavior assumed: 4 sites

Dose measured as function of distance using 3 sites -- rem meter; PNR-4; TEPC

Flux measured as function of distance using : 1 site --

Monte Carlo code

Distance from source dosimeter is exposed: 15 to $150 \mathrm{~cm}$

Type of dosimeter calibration:

Single calibration for all

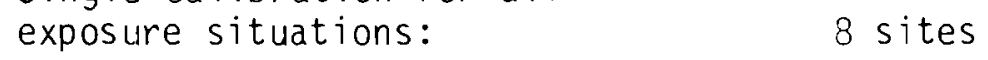

Energy correction factor applied: 8 sites

Method used for correction factor:

Ratio of 9-inch to 3-inch

polyethylene sphere responses: 7 sites

Ratio of TLD responses inside

dosimeter

Track length in NTA

Other:

l site -- exposed in work location where DE known

Are any types of internal audits used? For example, are dosimeters with known exposures to neutron or mixed neutron and gamma fields placed in the dosimetry system as "dummy" persons?

Yes -- please describe:

3 sites - 2 audit TLD reader with badges of known dose; 1 does blind audit of entire system, including records 
How are the dosimeters worn?

On belt around waist:

2 sites

Clipped to clothing on chest:

9 sites

As part of security credential:

5 sites

On necklace

On wrists:

1 site

What do you see as your problem areas for neutron dosimetry?

Energy response problem:

8 sites

Lack of sensitivity:

2 sites

Calibration problems:

4 sites

Accuracy problems (occasional

"flyers"):

4 sites

Gamma interference:

5 sites

0ther:

3 sites -- film fading; forearm dose -- estimated from $\mathrm{Y} / \mathrm{n}$ ratio; hand dosimeter problem

Please describe areas in which neutron dosimeters have been successfully used.

Response: TLD-albedo-detected neutrons undetected by NTA High-energy neutrons

Also useful as area monitors

TLD-albedo used successfully in Pu fabrication, accelerator

Do you think there will be a major impact on the dosimetry system used if there is a change in quality factors for neutrons? For example, will it be possible to correct for changes in QF for past exposures? 
Please give the names, addresses and telephone numbers of anyone in your organization engaged in neutron dosimetry research.

Response: 6 sites have persons working on neutron dosimetry problems

What are your ideas about the type of personnel neutron dosimeters to be used in the future? Where should future neutron dosimetry research be directed?

Response: More work should be done on TL dosimeters

Use of mixtures of dosimeters (e.g., TL $600 \& 300$ on combinations of filtered $600 \mathrm{~s}, 300 \mathrm{~s}$, and track etch)

Techniques of measurement and accurate dose-equivalent determination by field personnel

Accelerator site: 0ccupational neutron dose-equivalent determination is not usually a problem because the dose equivalent is currently very low, i.e., <100 mrem per year. Since only a small percentage of radiation workers need neutron monitoring, fission track damage and albedo (TLD) monitoring can be optimized for small number of workers. If regulations require monitoring below 0.5 rem per year, then the situation appears hopeless given present monitoring methods. 


\section{SURVEY PARTICIPANTS}

The following DOE sites participated in the personnel neutron dosimeter survey. Not all sites responded to the written dosimeter survey form; some responded by telephone interviews.

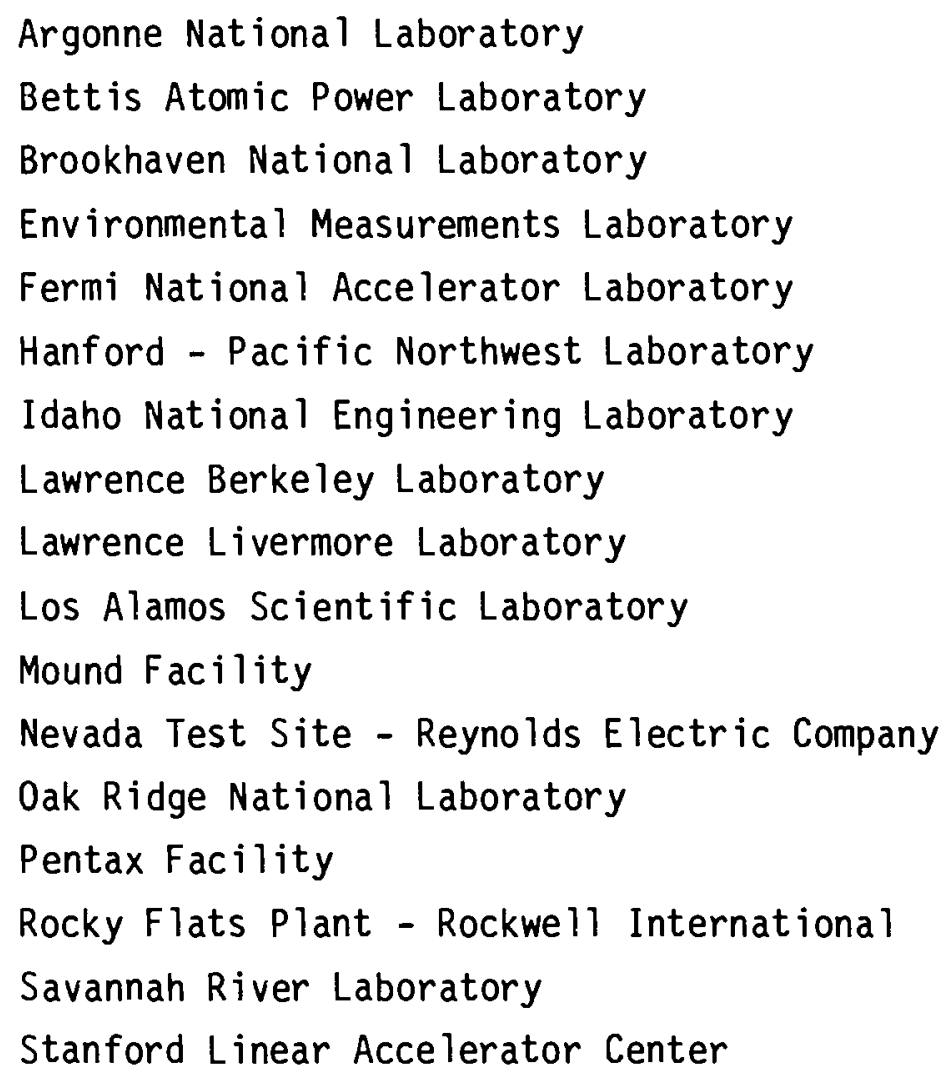




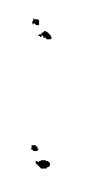




\section{DISTRIBUTION}

No. of

Copies

OFFSITE

A. A. Churm

DOE Patent Division

9800 South Cass Avenue

Argonne, IL 60439

R. C. Clusen

Ass istant Secretary for

Environment

U.S. Department of Energy

Washington, DC 20545

L. L. Brothers

Deputy Assistant Secretary for Environment

U.S. Department of Energy

Washington, DC 20545

G. P. Dix

Director, Operational \& Environmental Safety Division

U.S. Department of Energy

Washington, DC 20545

T. G. Frangos

Director, Office of Environmental Compliance \& Overview

U.S. Department of Energy

Washington, DC 20545

H. Hollister

Deputy Assistant Secretary for Research

U.S. Department of Energy

Washington, DC 20545
No. of

Copies

D. M. Ross

Branch Chief, Health Protection Branch

Operational \& Environmental Safety Division

U.S. Department of Energy Washington, DC 20545

100 E. J. Vallario

Assistant Chief/Manager, Health Physics Program

Operational and Environmental Safety Division

U.S. Department of Energy

Washington, DC 20545

R. Wood

Pollutant Characterization and Safety Research Division

U.S. Department of Energy

Washington, DC 20545

J. R. Roeder

Director, Operational Safety Division

U.S. Department of Energy

Albuquerque Operations Office

P.0. Box 5400

Albuquerque, NM 87115

B. L. Gage

Acting Chief, Operations

Branch

U.S. Department of Energy

Amarillo Area Office

P.0. Box 30030

Amari110, TX 79120 
No. of

Copies

R. M. Moser

Operational \& Environmental

Safety Division

U.S. Department of Energy

Chicago Operations Office

9800 South Cass Avenue

Argonne, IL 60439

B. D. Shipp

Director, Operational \&

Environmental Safety Division

U.S. Department of Energy

Chicago Operations Office

9800 South Cass Avenue

Argonne, IL 60439

G. R. Gartre 11

Operations Branch Chief

U.S. Department of Energy

Dayton Area Office

P.0. Box 66

Miamisburg, $\mathrm{OH} 45342$

R. J. Beers

Assistant Manager,

Environmental, Safety \&

Health Programs

U.S. Department of Energy

Idaho Operations office

550 Second Street

Idaho Falls, ID 83401

E. V. Beuhler

Chief, Operational Safety

Section

U.S. Department of Energy

Kansas City Area Office

P.0. Box 202,

Kansas City, MO 64141

A. Gallegos

Hea Ith \& Safety Coordinator

U.S. Department of Energy

Los Alamos Area Office

528 Thirty-Fifth Street

Los Alamos, NM 87544
No. of

Copies

H. E. Valencia

Assistant Area Manager, Office of Operations

U.S. Department of Energy

Los Alamos Area Office

528 Thirty-Fifth Street

Los Alamos, NM 87554

S. R. Elliott

Director, Office of Safety \& Health

U.S. Department of Energy

Nevada Operations Office

P.0. Box 14100

Las Vegas, NV 89114

W. H. Travis

Director, Safety \& Environmental Control Division

U.S. Department of Energy

Oak Ridge Operations Office

P.0. Box E

Oak Ridge, TN 37830

J. G. Stearns

Chief, Safety \& Environment Branch

U.S. Department of Energy

Rocky Flats Area Office

P.0. Box 928

Golden, CO 80401

A. R. Sneddon, Jr.

U.S. Department of Energy

Sandia Area Office

P.0. Box 5400

Albuquerque, NM 87115

C. D. Jackson

Director, Environment, Safety and Program Support Division

U.S. Department of Energy

San Francisco Operations office 1333 Broadway

Oakland, CA 94612 
W. A. Reese

Director, Safety \& Environment Division

U.S. Department of Energy

Savannah River Operations Office

P.0. Box A

Aiken, SC 29801

L. A. Sweeney

U.S. Department of Energy, Region I

Analex Bldg, Room 700

150 Causeway Street

Boston, MA 02114

R. J. Meaddough

U.S. Department of Energy, Region II

26 Federal Plaza, Room 3206

New York, NY 10007

R. Scottoline

U.S. Department of Energy, Region III

1421 Cherry Street, 10th Floor

Philadelphia, PA 19102

D. McCollister

U.S. Department of Energy, Region IV

1776 Peachtree St., NW

Atlanta, GA 30309

J. R. Ross, Jr.

U.S. Department of Energy, Region VI

P.0. Box 35228

2626 W. Mock ingbird Lane

Dallas, TX 75235

R. Brown

U.S. Department of Energy, Region VII

324 E. 11th Street

Kansas City, MO 64106
J. G. Leyba

U.S. Department of Energy, Region VIII

P.0. Box 26247, Belmar Branch

1075 S. Yukon Street

Lakewood, CO 80226

Safety Officer

U.S. Department of Energy, Region IX

333 Market Street

San Francisco, CA 94105

A. Denson

U.S. Department of Energy, Region $X$

1992 Federal Bldg

915 Second Street

Seattle, WA 98147

F. Hajnal

U.S. Department of Energy

Environmental Measurements

Laboratory

376 Hudson Street

New York, NY 10014

W. Lowder

U.S. Department of Energy

Environmental Measurements

Laboratory

376 Hudson Street

New York, NY 10014

J. E. McLaughlin

U.S. Department of Energy

Environmental Measurements

Laboratory

376 Hudson Street

New York, NY 10014

J. P. Cusimano

Health Physics Laboratory

U.S. Department of Energy

P.0. Box 2108

Idaho Falls, ID 83401 
T. J. Glasson

U.S. Department of Energy

Knolls Atomic Power Laboratory

P.0. Box 1072

Schenectady, NY 12301

J. F. Koury

U.S. Department of Energy

Pittsburgh Naval Reactors Office

P.0. Box 109

W. Mifflin, PA 15122

D. J. Hamilla

U.S. Department of Energy

Schenectady Naval Reactors office

P.0. Box 1069

Schenectady, NY 12301

D. E. Jones

U.S. Department of Energy

B 1dg. CF 690

550 Second Street

Idaho Falls, ID 83401

27 DOE Technical Information Center

R. B. Schwartz

U.S. National Bureau of Standards

Washington, DC 20234

R. E. Alexander

Chief, Occupational Health Standards Branch

U.S. Nuclear Regulatory Commission

Washington, DC 20555

S. Block

U.S. Nuclear Regulatory Commission

Washington, DC 20545
J. Foulke

U.S. Nuclear Regulatory Commission

7915 Eastern Avenue, Room 1014

Silver Spring, MD 20555

H. J. Pettengill

U.S. Nuclear Regulatory Commission

Rockville, MD 20850

M. D. Voss

Ames Laboratory

Iowa State University

Ames, IA 50011

E. H. Dolacek

Argonne National Laboratory

9700 South Cass Avenue

Argonne, IL 60439

D. P. O'Neil

Argonne National Laboratory

9700 South Cass Avenue

Argonne, IL 60439

C. S. Abrams

Argonne National Laboratory, Idaho Site

P.0. Box 2528

Idaho Falls, ID 83401

W. R. Harris

Bett is Atomic Power Laboratory P.0. Box 79

West Mifflin, PA 15122

R. M. Myzik

Bett is Atomic Power

Laboratory

P.0. Box 79

W. Mifflin, PA 15122

V. P. Bond

Brookhaven National Laboratory Upton, NY 11973 
No. of

Copies

C. B. Meinhold

Safety \& Environmenta 1

Protection Division

Brookhaven National Laboratory

Upton, NY 11973

L. F. Phillips

Brookhaven National Laboratory

Bldg. 535A

Upton, NY 11973

E. Geiger

Eber line Instrument Corporation

Santa Fe, NM 87501

L. Johnson

EG\&G Idaho, Inc.

P.0. Box 1625

Idaho Falls, ID 83401

B. Rich

EG\&G Idaho, Inc.

P.0. Box 1625

İdaho Falls, ID 83401

W. M. Quam

EG\&G Inc.

130 Robin Hill Road

Goleta, CA 93017

H. P. Boiter

Health Physics Department

E. I. du Pont de Nemours \& Co Savannah River Plant

Aiken, SC 29801

R. M. Hall

E. I. du Pont de Nemours \& Co

Savannah River Plant

Aiken, SC 29801

J. Hoy

E. I. du Pont de Nemours \& Co

Savannah River Plant

Aiken, SC 29801
No. of

Copies

W. C. Reinig

E. I. du Pont de Nemours \& Co

Savannah River Plant

Aiken, SC 29801

L. M. Lederman

Fermi National Accelerator Laboratory

P.0. Box 500

Batavia, IL 60510

A. L. Read

Fermi National Accelerator Laboratory

P.0. Box 500

Batavia, IL 60510

S. Velen

Fermi National Accelerator Laboratory

P.0. Box 500

Batavia, IL 60510

E. P. Forest

General Electric Company, Neutron Devices Dept.

P.0. Box 11508

St. Petersburg, FL 33733

A. C. Lucas

Harshaw Chemical Company

6801 Cochran Road

Solon, $\mathrm{OH} 44139$

J. Stiver

KMS Fusion, Inc.

3941 Research Park Drive

P.0. Box 1567

Ann Arbor, MI 48106

J. McCaslin

Lawrence Berkeley Laboratory

B1dg. 75B

1 Cyclotron Road

Berkeley, CA 94720 
No. of

Copies

R. V. Griffith

Hazards Control Department

Lawrence Livermore Laboratory

$L-520$

P.0. Box 808

Livermore, CA 94550

D. E. Hankins

Lawrence Livermore Laboratory

$L-383$

P.0. Box 808

Livermore, CA 94550

H. W. Patterson

Lawrence Livermore Laboratory

P.0. Box 808

Livermore, CA 94550

J. E. Dummer

Hea Ith Physics Group

LoS Alamos Scientific Laboratory

Los Alamos, NM 87545

J. N. P. Lawrence

Los Alamos Scientific

Laboratory

MS-401

Los Alamos, NM 87545

G. L. Voelz

Los Alamos Scientific Laboratory

P.0. Box 1663

Los Alamos, NM 87545

R. Taylor

Health Protection Operation

Lovelace ITRI

P.0. Box 5890

Albuquerque, NM 87115

M. Hill

Mason and Hanger - Silas Mason Company, Inc.

P.0. Box 30020

Amarillo, TX 79177
No. of

Copies

\author{
M. S. Johnson \\ Mason \& Hanger - Silas Mason \\ Company, Inc.
}

P.0. Box 30020

Amarillo, TX 79177

P. C. Adams

Monsanto Research Corporation

P. 0. Box 32

Miamisburg, $\mathrm{OH} 45342$

M. L. Mullins

Monsanto Research Corporation P.0. Box 32

Miamisburg, $\mathrm{OH} 45342$

R. C. Heatherton

National Lead Company of Ohio P.0. Box 39158

Cincinnati, $\mathrm{OH} 45239$

A. E. Bicker

Nevada Test Site

Mercury, NV 89023

J. C. Bailey

Oak Ridge Gaseous Diffusion Plant

P.0. Box $P$

Oak Ridge, TN 37830

J. A. Auxier

Oak Ridge National Laboratory

P.0. Box $X$

Oak Ridge, TN 37830

H. W. Dickson

Oak Ridge National Laboratory

P.0. Box X

Oak Ridge, TN 37830

E. D. Gupton

Oak Ridge National Laboratory P.0. Box $X$

Oak Ridge, TN 37803 
No. of

Copies

J. Wells

Reynolds Electrical and Engineer ing Company

P.0. Box 14400

Las Vegas, NV 89114

R. J. Tutt le

Rockwe 11 Internationa 1

Energy Systems Group

8900 DeSoto Avenue

Canoga Park, CA 91304

R. B. Falk

Rockwe 11 Internationa 1

Rocky Flats Plant

P.0. Box 464

Golden, CO 80401

E. Putzier

Health Sciences and

Industrial Safety

Rockwe 11 International

Rocky Flats Plant

P. 0 . Box 464

Golden, C0 80401

R. E. Yoder

Rockwe 11 International

Rocky Flats Plant

P.0. Box 464

Golden, CO 80401

W. D. Burnett

Sandia Laboratories

P.0. Box 5800

Aibuquerque, NM 87115

D. D. Busick

Stanford Linear Accelerator

P.0. Box 4349

Stanford, CA 94305

J. D. McLendon

Radiation Safety

Union Carbide Corporation

P.0. Box $Y$

Oak Ridge, TN 37830
No. of

Copies

P. Deluca

University of Wiscons in

Madison, WI 53706

R. E. Apfel

Department of Engineering and Applied Sciences

Yale University

New Haven, CT 06520

\section{FORE IGN}

F. N. Flakus

A-1011 Vienna

P.0. Box 645

AUSTRIA

E. Piesch

Gesellschaft fur

Kernforschung mbH

Postfach 3640

D-7514 Leopoldshafen

FEDERAL REPUBLIC OF GERMANY

ONSITE

5 DOE Richland Operations Office

H. E. Ransom

J. L. Rhoades

M. W. Tiernan

M. G. White

G. R. Yesberger

2 Rockwell Hanford Operations

W. F. Heine

G. C. Owens

UNC Nuclear Industries, Inc.

T. E. Dabrowski 
No. of

Copies

4 Hanford Engineering Development

Laboratory

R. 0. Budd

D. E. Clark

R. C. Smith

J. N. Strode

38 Pacific Northwest Laboratory

J. L. Baer

W. J. Bair

L. W. Brackenbush (10)

P. E. Bramson

F. M. Cummings

J. P. Cor ley

G. W. R. Endres

L. G. Faust

J. J. Fix

D. M. Fleming

W. A. Glass

A. J. Haverfield

K. R. Heid

D. L. Haggard

J. J. Jech

R. L. Kathren

H. V. Larson

L. L. Nichols

J. M. Selby

C. M. Unruh

W. C. Wiley

R. C. Yoder

Technical Information (5)

Publishing Coordination (2) 